ARTICLE

\title{
TGF- $\beta$ activation by bone marrow-derived thrombospondin-1 causes Schistosoma- and hypoxia-induced pulmonary hypertension
}

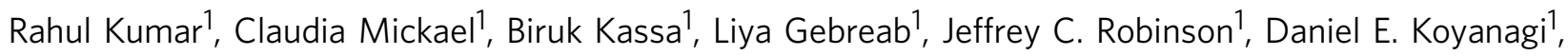
Linda Sanders ${ }^{1}$, Lea Barthel ${ }^{2}$, Christina Meadows ${ }^{3}$, Daniel Fox ${ }^{3}$, David Irwin ${ }^{4}$, Min Li ${ }^{4}$, B. Alexandre McKeon ${ }^{4}$, Suzette Riddle4, R. Dale Brown ${ }^{4}$, Leslie E. Morgan ${ }^{3}$, Christopher M. Evans ${ }^{3}$, Daniel Hernandez-Saavedra ${ }^{1}$, Angela Bandeira ${ }^{5}$, James P. Maloney ${ }^{3}$, Todd M. Bull ${ }^{3}$, William J. Janssen ${ }^{2}$, Kurt R. Stenmark ${ }^{4}$, Rubin M. Tuder ${ }^{1} \&$ Brian B. Graham ${ }^{1}$

Pulmonary arterial hypertension (PAH) is an obstructive disease of the precapillary pulmonary arteries. Schistosomiasis-associated PAH shares altered vascular TGF- $\beta$ signalling with idiopathic, heritable and autoimmune-associated etiologies; moreover, TGF- $\beta$ blockade can prevent experimental pulmonary hypertension (PH) in pre-clinical models. TGF- $\beta$ is regulated at the level of activation, but how TGF- $\beta$ is activated in this disease is unknown. Here we show TGF- $\beta$ activation by thrombospondin-1 (TSP-1) is both required and sufficient for the development of PH in Schistosoma-exposed mice. Following Schistosoma exposure, TSP-1 levels in the lung increase, via recruitment of circulating monocytes, while TSP-1 inhibition or knockout bone marrow prevents TGF- $\beta$ activation and protects against PH development. TSP-1 blockade also prevents the PH in a second model, chronic hypoxia. Lastly, the plasma concentration of TSP-1 is significantly increased in subjects with scleroderma following PAH development. Targeting TSP-1-dependent activation of TGF- $\beta$ could thus be a therapeutic approach in TGF- $\beta$-dependent vascular diseases.

\footnotetext{
${ }_{1}^{1}$ Program in Translational Lung Research, Department of Medicine, Anschutz Medical Campus, Building RC2, 9th floor, 12700 East 19th Avenue, Aurora, Colorado 80045, USA. ${ }^{2}$ Department of Medicine, National Jewish Health, 1400 Jackson Street, Denver, Colorado 80206, USA. ${ }^{3}$ Department of Medicine, Anschutz Medical Campus, Building RC2, 9th floor, 12700 East 19th Avenue, Aurora, Colorado 80045, USA. ${ }^{4}$ Department of Pediatrics and Medicine, Cardiovascular Pulmonary Research Laboratory, Anschutz Medical Campus, Building RC2, 8th floor, 12700 East 19th Avenue, Aurora, Colorado 80045, USA. ${ }^{5}$ Department of Medicine, Memorial S. Jose Hospital, Universidade de Pernambuco, Avenida Governador Agamenon Magalhães, 2291, Recife PE 50070-901, Brazil. Correspondence and requests for materials should be addressed to R.K. (email: rahul.2.kumar@ucdenver.edu) or to B.B.G. (email: brian.graham@ucdenver.edu).
} 
P ulmonary arterial hypertension (PAH) is a progressive disease of the precapillary pulmonary vasculature, resulting in resistance to blood flow and eventual right heart failure and death ${ }^{1}$. Current therapies for this condition are largely vasodilators, which treat symptoms but do not adequately address the underlying drivers of disease pathogenesis and progression. In addition to vasoconstriction, the pathobiology of PAH includes inflammation and excessive proliferation with reduced apoptosis of lung vascular cells ${ }^{2}$.

One central cytokine linked to all of these pathologies is transforming growth factor (TGF)- $\beta$. TGF- $\beta$ family mutations underlie familial forms of the disease, and dysregulated TGF- $\beta$ signalling is present in non-heritable forms including idiopathic, autoimmune and infectious etiologies ${ }^{3-5}$. Blockade of TGF- $\beta$ is effective in multiple pre-clinical models of experimental pulmonary hypertension $(\mathrm{PH})$, including experimental hypoxia, monocrotaline and exposure to the parasite Schistosoma mansoni $i^{3,6,7}$. Direct inhibition of TGF- $\beta$ signalling clinically has been pursued in multiple diseases including autoimmune fibrosis and oncology ${ }^{8,9}$. However, as TGF- $\beta$ is ubiquitously expressed, it would be ideal to target its pathologic, compartment-specific effects.

TGF- $\beta$ is highly regulated at the level of activation ${ }^{10}$. Latent pro-TGF- $\beta$ is synthesized and secreted bound to the latencyassociated propeptide (LAP) ${ }^{11}$. Multiple proteins can activate TGF- $\beta$ by removing the LAP, including the integrins $\alpha_{v} \beta_{6}$ and $\alpha_{v} \beta_{8}$, and the thrombospondins (TSPs) ${ }^{10-16}$. It remains unclear how pathologic TGF- $\beta$ is activated in PAH, specifically in the perivascular space where it would have localized paracrine effects on the vascular cells.

We hypothesized that TSP-1 (protein name abbreviated as TSP-1, encoded by the Thbs1 gene) is required for the activation of TGF- $\beta$ in Schistosoma-induced PH. Prior studies have shown that TSP-1 is necessary for hypoxia-induced $\mathrm{PH}^{17-19}$, but the role of TSP-1 remains unclear: as a large, multimeric protein, TSP-1 can also interact with other proteins including its receptors $\mathrm{CD} 36$ and $\mathrm{CD} 47$, which could mediate $\mathrm{PH}$ development ${ }^{20}$. Other studies have suggested TSP-1 may regulate NO and endothelin-1

a
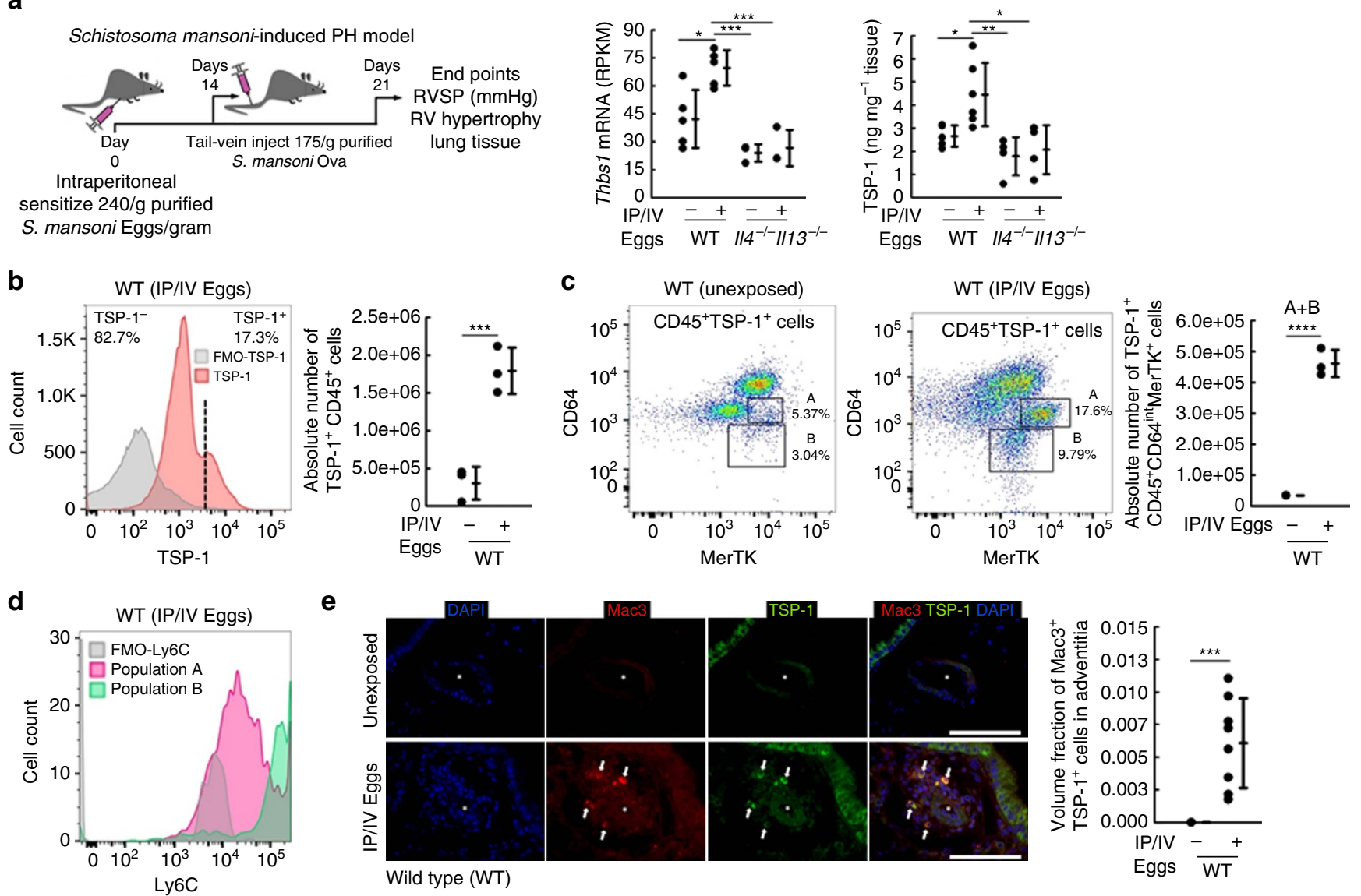

Figure 1 | Effect of S. mansoni exposure on TSP-1 expression and localization. (a) Whole-lung concentrations of Thbs1 mRNA by RNA-seq ( $n=5,5,3$ and 3 mice/group, respectively; RPKM: reads per kilobase per million mapped reads; analysis of variance (ANOVA) $P<0.001$, with post hoc Tukey tests shown) and protein concentration by ELISA ( $n=5,6,4$ and 4 mice/group, respectively; ANOVA $P<0.005$, with post hoc Tukey tests shown) in wild-type and $114^{-/-} \| 13^{-/-}$mice unexposed or with Schistosoma mansoni-induced $\mathrm{PH}$. (b) Representative histogram and quantification of number of CD45 ${ }^{+}$singlet cells from whole-lung tissue digest, which stain positive for intracellular TSP-1 by flow cytometry from unexposed or Schistosoma exposed mice (FMO: fluorescence minus one, that is, no TSP- 1 antibody; $n=3$ mice/group; $t$-test). (c) Sorting on the CD45 ${ }^{+}$TSP- $1^{+}$population in unexposed and Schistosomaexposed samples identifies the recruited TSP-1 ${ }^{+}$cells to be CD64 int MerTK ${ }^{+}$with two subpopulations, labelled ' $\mathrm{A}^{\prime}$ and ' $\mathrm{B}^{\prime}$ as shown ( $n=3 /$ group; $t$-test). (d) Histogram of Ly6C expression intensity in the ' $A$ ' and ' $B$ ' populations, relative to FMO (fluorescence minus one: no Ly6C antibody; representative of $n=3$ repetitions/group). (e) Representative immunostaining for TSP-1 and Mac3 (macrophage marker), and quantification of the volume fraction of TSP-1 ${ }^{+}$Mac3 ${ }^{+}$cells in the adventitia of vessels by stereology (asterisk: vessel lumen; arrows: representative positive double-stained cells; scale bars: $50 \mu \mathrm{m} ; n=5$ and 8 mice/group, respectively; $t$-test). (Mean \pm s.d. plotted; $P$ values: ${ }^{\star} P<0.05 ;{ }^{\star \star} P<0.01 ;{ }^{\star \star \star} P<0.005,{ }^{\star \star \star \star} P<0.001 ; \mathrm{IP} / \mathrm{IV}$ : intraperitoneal/intravenous S. mansoni eggs). 
signalling via interactions with CD47 (refs 16,18,21). TSP-1 can alter the vascular matrix by disrupting endothelial cell junctions and promoting migration of cells including fibroblasts and smooth muscle cells ${ }^{17}$. Thbs1 polymorphisms have also been identified in heritable $\mathrm{PAH}^{22}$. However, the potential role of TSP1 as the activator of TGF- $\beta$ in PH and in particular PH caused by the parasite $S$. mansoni has not been addressed.

Schistosoma-induced PAH remains a major health problem due to the unfortunate persistent prevalence of this neglected tropical disease. The high prevalence of schistosomiasis results from economic, infrastructure, cultural and political barriers to the effective widespread use of antihelmintic medication and prevention strategies in endemic areas ${ }^{23}$. Mechanistic studies of Schistosoma-induced PAH are highly relevant to patients with the disease and to the broad PH field.

We utilized a robust and reproducible mouse model of Schistosoma-induced PAH, which employs intraperitoneal sensitization followed by intravenous challenge with $S$. mansoni eggs $^{3,24,25}$. Schistosoma eggs drive a strong Type-2 inflammation ${ }^{26}$, which we have previously shown is necessary for disease pathogenesis ${ }^{25}$. This model, while recapitulating key features of inflammatory human vascular disease, does not include liver disease, which simultaneously occurs with the natural form of infection-thereby allowing for the investigation of this intrapulmonary antigen-inflammation-vascular disease axis. In addition, to validate and expand the significance of our findings, we analysed chronic hypoxia murine and bovine experimental models of PH. Finally, in support of a potential pathologic role of TSP-1 in human clinical disease, we identified an increase in plasma TSP-1 levels in scleroderma patients before and after the development of PAH.

\section{Results}

Th2 immunity drives TSP-1 ${ }^{+}$monocytes in Schistosoma-PH. We initially assessed TSP-1 levels in the lung. Whole-lung messenger RNA (mRNA) quantification revealed significantly higher Thbs 1 transcript quantity in Schistosoma-exposed wild-type mice compared with unexposed mice, which was confirmed at the protein level (Fig. 1a). Il ${ }^{-/-} I l 13^{-/-}$mice, which we have shown have less TGF- $\beta$ signalling and consequently $\mathrm{PH}$ following Schistosoma exposure ${ }^{25}$, did not have an increase in lung TSP-1, indicating that interleukin (IL)-4/IL-13 signalling acts proximally to TSP-1 (Fig. 1a). Of the other TSPs, whole-lung Thbs4 (neuronal) mRNA expression was increased and Thbs 2 and Thbs3 transcript levels remained unchanged (Supplementary Fig. 1). Flow cytometry of cell-dispersed murine lung revealed a new population with intracellular TSP-1 expression following Schistosoma exposure (Fig. 1b,c and Supplementary Fig. 2).

These TSP-1 ${ }^{+}$cells were identified to be two subpopulations (Fig. 1d). One was Ly6C ${ }^{\text {hi }} \mathrm{CD} 64^{\text {lo }}{ }^{\text {MerTK }}{ }^{\text {int }}$ cells, which are consistent with intravascular $\mathrm{Ly}^{6} \mathrm{C}^{+}$monocytes. The other was ${ }_{\text {Ly6C }}{ }^{\text {int }}$ CD6 ${ }^{\text {int }}$ MerTK $^{\text {hi }}$ cells, which are consistent with Ly6C ${ }^{+}$ monocytes that had been recruited into the parenchyma, and then evolved into a more macrophage-like phenotype ${ }^{27,28}$. In contrast, we found that $I l 4^{-/-} I l 13^{-}-$mice have substantially fewer TSP- $1^{+}$cells in general, and $\mathrm{TSP}_{-1}{ }^{+} \mathrm{Ly}_{6 \mathrm{C}}{ }^{+}$monocytes specifically (Supplementary Fig. 3). Reverse transcription-PCR (RT-PCR) of sorted cells from this population from wild-type mice confirmed a high abundance of Thbs1 mRNA (Supplementary Fig. 4). On the other hand, there was no change in extracellular TSP-1 staining with Schistosoma exposure (Supplementary Fig. 5)—suggesting these cells were synthesizing TSP-1 themselves (as has been previously reported with activated monocytes in vitro ${ }^{29}$ ) rather than taking up the protein from their microenvironment. Immunostaining identified a significant increase in the density of co-expressing $\mathrm{TSP}-1^{+} \mathrm{Mac} 3^{+}$cells within the pulmonary vascular adventitia following Schistosoma exposure (Fig. 1e and Supplementary Fig. 6), indicating the localization of these recruited cells to the adventitial compartment.

Blockade of TSP-1 protects mice from Schistosoma-PH. TSP-1 activates TGF- $\beta$ via a physical interaction between the peptide KRFK sequence in the type I repeats domain of TSP-1 and a cognate Leu-Ser-Lys-Leu (LSKL) sequence in the LAP, which results in release of active TGF- $\beta$. Synthetic LSKL has been shown to competitively inhibit specifically this TGF- $\beta$ activation function of TSP-1 (refs 12,13). We treated Schistosoma-exposed and unexposed mice with LSKL (or control peptide Ser-Leu-Leu-Lys, or SLLK) ${ }^{12,30}$, starting the day before intravenous egg augmentation as the triggering event for the $\mathrm{PH}$ phenotype. We observed that LSKL protected against the increase in right ventricular systolic pressure (RVSP) and pulmonary vascular media thickness resulting from Schistosoma exposure (Fig. 2a). Both Il4/Il13 mRNA and IL-4/IL-13 protein levels were not altered by the TSP-1 blockade (Supplementary Fig. 7), confirming TSP-1 is downstream of IL-4/IL-13 as suggested in Fig. 1a above. To test whether bone marrow (BM)-derived cells (including $\mathrm{Ly} \mathrm{C}^{+}$monocytes) are the source of pathologic TSP-1, we transplanted Thbs $1^{-/-}$(or wild type) BM into lethally irradiated wild-type recipient mice. While BM transplant alone did not alter the Schistosoma-PH phenotype of wild-type mice, wild-type recipients of Thbs $1^{-}-\mathrm{BM}$ were significantly protected from Schistosoma-PH with decreased RVSP and vascular media thickness (Fig. 2b); these findings support the concept that BMderived cells are the predominant source of TSP-1 in Schistosoma-induced PH. Moreover, we also verified that in BM recipient mice, radiation-induced lung perivascular or parenchymal fibrosis (which could have occurred via a TSP-1 independent mechanism, or could have independently triggered TSP-1 expression) did not contribute to our findings (Supplementary Fig. 8).

To address whether TSP-1-mediated TGF- $\beta$ activation suffices to produce the $\mathrm{PH}$ phenotype seen in Schistosomainduced $\mathrm{PH}$, we then administered synthetic KRFK peptide to wild-type recipients of Thbs $1^{-/-} \mathrm{BM}$ : in the absence of TSP-1, KRFK serves as a gain-of-function mimicking the TGF- $\beta$-activation function of TSP-1 (refs 12,13). We found that mice reconstituted Thbs $1^{-/}$BM regained the $\mathrm{PH}$ phenotype following Schistosoma exposure when treated with KRFK (Fig. 2c), albeit to a lesser extent than wild-type mice, potentially due to inadequate dose or distribution of the peptide. LSKL treatment and wild-type recipients of Thbs $1^{-/-}$BM also had less granulomatous inflammation, without evidence of excessive inflammation that could occur if TGF- $\beta$ blocked immune activation (Supplementary Figs 9 and 10). Vascular intima thickness, which is generally less affected than the media in this model $^{3}$, was not significantly altered (Supplementary Fig. 11). There were similar residual egg burdens 1 week after intravenous augmentation, suggesting unimpaired parasite egg clearance (Supplementary Figs 12 and 13). There were also no significant differences in left ventricular pressure, right ventricular diastolic pressure, heart rate or body weight between exposed and unexposed mice treated with LSKL or receiving Thbs $1^{-/-}$BM (Supplementary Tables 1 and 2), and there were no apparent detrimental effects of either in unexposed mice. (We relied on Thbs $1^{-/-} \mathrm{BM}$ transplanted mice only as we found that globally-deficient Thbs $1^{-/}$mice have a baseline lung phenotype that includes emphysema and PH: Supplementary Fig. 14.) 
a
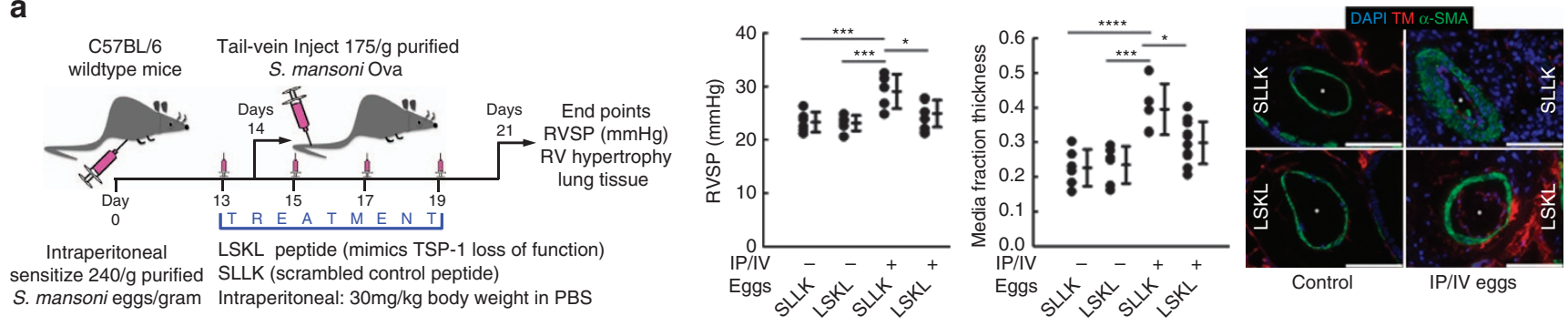

b
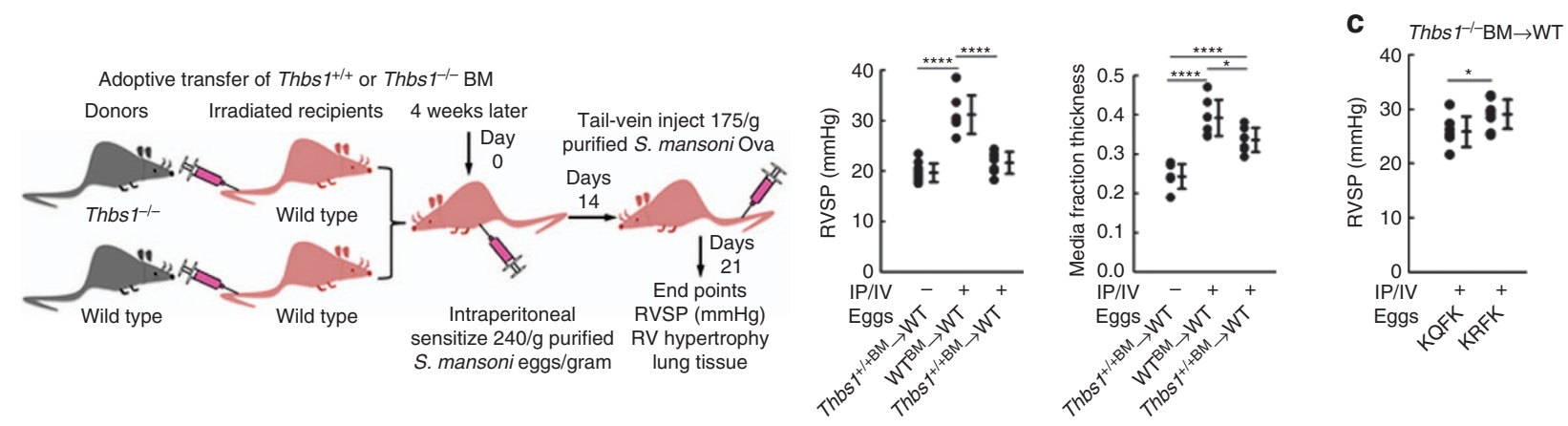

d
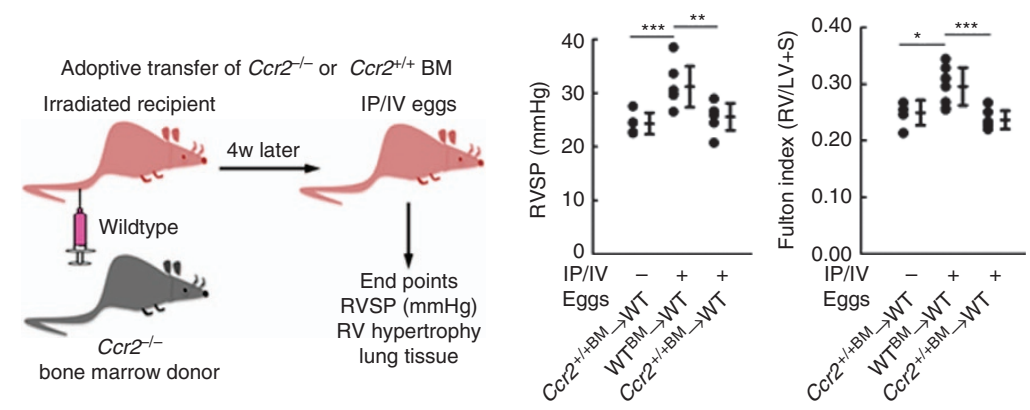

Figure 2 | Effect of TSP-1 blockade on Schistosoma-induced pulmonary hypertension. (a) Right ventricular systolic pressure (RVSP) of unexposed or Schistosoma-exposed wild-type (WT) mice treated with LSKL, which inhibits the TGF- $\beta$ activation function of TSP-1 (or equivalent volume of scrambled control peptide SLLK), and quantitative fractional thickness of the pulmonary vascular media by morphometry $(n=6,6,5$ and 11 mice/group, respectively; analysis of variance (ANOVA) $P<0.001$ for both RVSP and media thickness, with post hoc Tukey tests shown; asterisks: vessel lumen; scale bars: $50 \mu$ m). (b) RVSP and media thickness in irradiated WT recipients of either WT or Thbs $1^{-/}$- bone marrow (BM), followed by no treatment or Schistosoma exposure $(n=10,7$ and 7 mice/group, respectively; ANOVA $P<0.001$ for both RVSP and media thickness, with post hoc Tukey tests shown). (c) RVSP in WT recipients of Thbs $1^{-/-}$BM, followed by Schistosoma exposure, and then treated with either KRFK, which mimics the TGF- $\beta$ activation function of TSP-1 (or equivalent volume of control peptide KQFK; $n=7$ and 8 mice/group, respectively; $t$-test). (d) RVSP and Fulton index in irradiated WT recipients of either WT or $\mathrm{Ccr}^{-/-}$BM, followed by no treatment or Schistosoma exposure (the data for WT recipients of WT BM are the same data shown in $\mathbf{b} ; n=5,7$ and 7 mice/group, respectively; ANOVA $P<0.001$ for both RVSP and media thickness, with post hoc Tukey tests shown). (Mean \pm s.d. plotted; $P$ values: ${ }^{\star} P<0.05$; ${ }^{\star \star} P<0.01,{ }^{\star \star \star} P<0.005,{ }^{\star \star \star \star} P<0.001 ; \mathrm{IP} / \mathrm{IV}$ : intraperitoneal/intravenous S. mansoni eggs).

Blocking Ly6C $^{+}$monocytes protects against Schistosoma-PH. Since we found evidence that BM-derived $\mathrm{Ly}^{+} \mathrm{C}^{+}$monocytes were the source of TSP-schistosomiasis-induced $\mathrm{PH}$, we investigated the expression of chemokines that can recruit these cells to the lung perivascular compartment; we found higher mRNA levels of $\mathrm{Ccl} 2, \mathrm{Ccl} 7$ and $\mathrm{Ccl} 12$ (the ligands for CCR2, the receptor on $\mathrm{Ly}_{6 \mathrm{C}}{ }^{+}$monocytes) in sorted tissue or interstitial macrophages specifically, (Supplementary Fig. 15). Furthermore, we detected higher levels of CCR2 and its ligands in whole-lung lysates following Schistosoma exposure (Supplementary Fig. 16).

To interrogate the role of $\mathrm{Ly}_{6 \mathrm{C}}{ }^{+}$monocytes, we blocked the recruitment of these cells by Ccr 2 deficiency in the $\mathrm{BM}$ compartment specifically. We observed wild-type recipients of Ccr $2^{-/-}$BM had total lung IL-4 and IL-13 content similar to that in wild-type mice following Schistosoma exposure (Supplementary Fig. 17a-d), and by flow cytometry, they had an increase in intravascular $\mathrm{Ly}_{6 \mathrm{C}}{ }^{+}$monocytes, similar to that seen in wild-type mice (Supplementary Fig. 18a). Importantly, in wild-type recipients of $C c r 2^{-/-}$BM compared with wild-type mice following Schistosoma exposure, there were fewer monocytes recruited into the parenchyma by flow cytometry and fewer adventitial TSP- $1^{+} \mathrm{Mac}^{+}$cells by immunostaining (Supplementary Fig. 18a,b). In wild-type recipients of $\mathrm{Ccr} 2^{-/-}$ $\mathrm{BM}$, the expression of whole-lung TSP-1 protein did not increase following Schistosoma exposure compared with unexposed Ccr $2^{-1-}$ BM recipients (although Thbs 1 mRNA increased; Supplementary Fig. 17e,f). This block in Ly6C $^{+}$monocyte recruitment resulted in protection against Schistosoma-PH with less RVSP and RV hypertrophy, and had a trend towards less pulmonary vascular remodelling, as compared with wild-type recipients of wild-type BM (Fig. 2d and Supplementary Fig. 19).

Monocyte-derived TSP-1 is regulated by $\mathrm{Hif} 2 \alpha$. As a recent report suggested TSP-1 is regulated by HIF $2 \alpha^{17}$, we assessed the phenotype of mice with macrophage/monocyte-specific Hif2 $\alpha$ 
deficiency (Epas $1^{f l / f l} \times$ Lyz2-Cre). We found these mice had significantly less whole-lung Thbs 1 mRNA and a partial decrease in TSP-1 protein expression, accompanied by lower RVSP, decreased vascular media thickness, and smaller granuloma volumes following Schistosoma exposure (Fig. 3a and Supplementary Fig. 20). Interestingly, flow cytometry of cell-dispersed lung from these mice following Schistosoma exposure revealed fewer TSP-1 ${ }^{+}$cells in general (Fig. 3b), and no increase in the TSP- $1^{+} \mathrm{Ly}_{6 \mathrm{C}}{ }^{+}$monocyte population as had been seen in wild-type mice exposed to Schistosoma (Fig. $3 \mathrm{c}$ and Supplementary Fig. 21a). Similarly, there were fewer pulmonary adventitial TSP $-1^{+} \mathrm{Mac}^{+}$cells by immunostaining compared with wild-type Schistosoma-exposed mice (Fig. 3d and Supplementary Fig. 21b). We did also find suppression of whole-lung Thbs 1 mRNA and detected partial reduction of TSP-1 protein in mice with macrophage/monocyte-specific Hifl $\alpha$ deficiency (Hifl $\alpha^{f l / f l}$ x Lyz2-Cre) (Supplementary Fig. 22).
TSP-1 activates TGF- $\boldsymbol{\beta}$ in Schistosoma-PH. To determine if the pathologic function of TSP- 1 correlates with TGF- $\beta$ activation, we quantified the concentration of active TGF- $\beta$ in the lungs of mice using a reporter cell line with a truncated human PAII promoter fused to firefly luciferase ${ }^{31}$. PAI1 responds to multiple TGF- $\beta$ isoforms ${ }^{32-34}$; we have previously found only Tgfb1 mRNA to be upregulated in Schistosoma- $\mathrm{PH}^{3}$. We used recombinant TGF- $\beta 1$ to correlate luciferase activity with TGF- $\beta$ concentration $\left(r^{2}=0.9739\right.$; Fig. 4a). Whole-murine lung lysates were added to the culture media of these reporter cells to determine the concentration of active TGF- $\beta$ in each. At the same time, duplicate samples were heat-treated to activate all TGF- $\beta$, to measure total TGF- $\beta$ concentration. Schistosoma exposure alone increased both active and total TGF- $\beta$ concentrations (Fig. 4a). These increases were significantly lessened by LSKL treatment (Fig. 4b). No change in TGF- $\beta$ concentrations occurred with LSKL treatment of control mice. We observed parallel changes in the whole-lung expression of murine Pail mRNA a
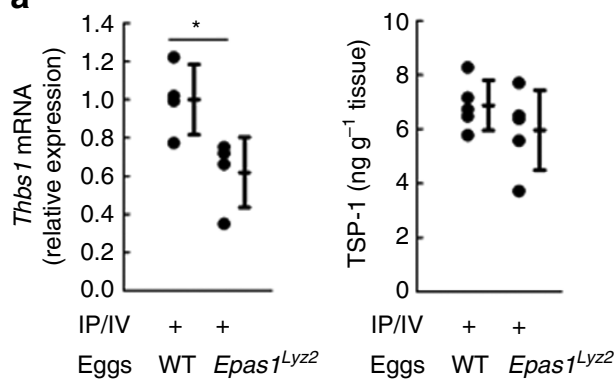

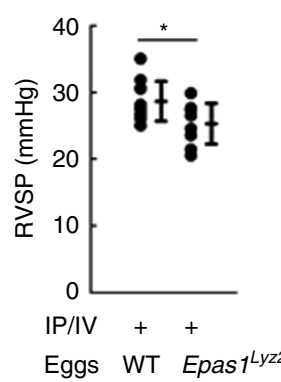

b

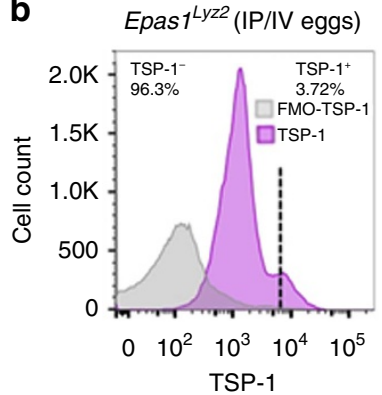

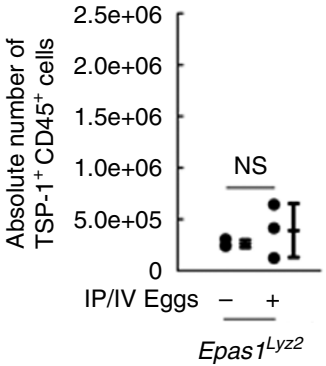

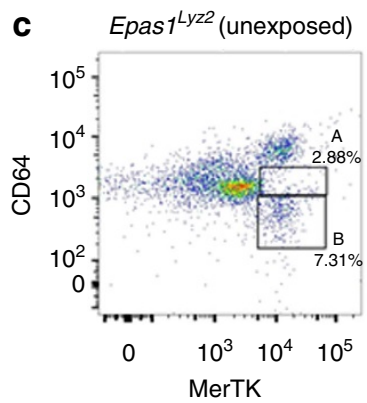

C

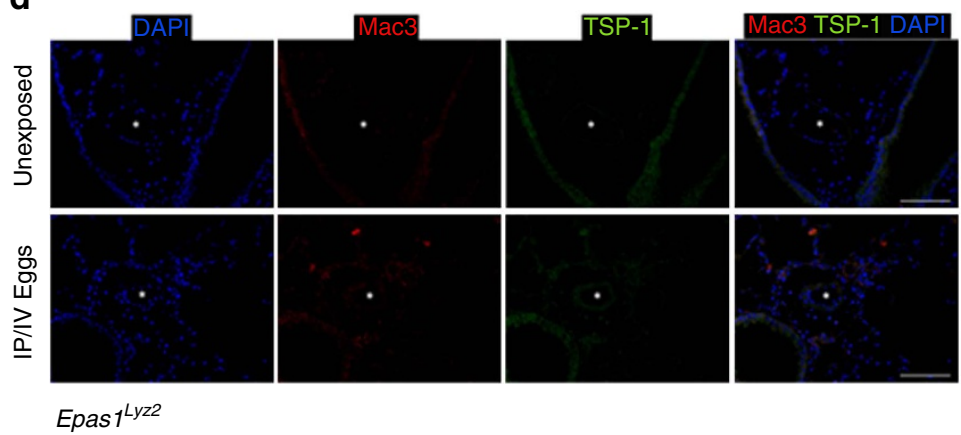

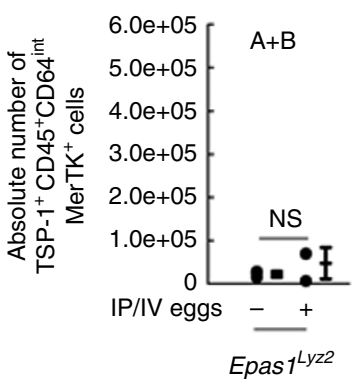

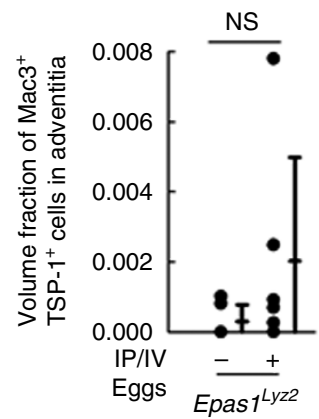

Figure 3 | Pathologic TSP-1 is regulated by HIF2 $\alpha$ in Schistosoma-induced pulmonary hypertension. (a) Whole-lung Thbs1 mRNA quantity by RT-PCR

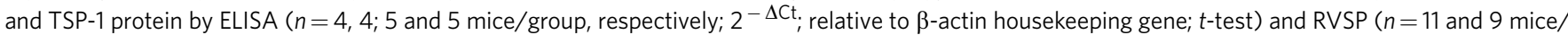
group, respectively; $t$-test) in Epas $f^{f / f l} \times$ Lyz2-Cre mice (abbreviated as Epas $7^{L y z 2}$ ) either unexposed or Schistosoma-exposed. (b) Representative histogram and quantification of number of CD45 ${ }^{+}$singlet (FMO: no TSP-1 antibody; three repetitions/group, $y$ axis is similar to wild-type data in Fig. 1b) cells from whole-lung tissue digest, which stain positive for intracellular TSP-1 by flow cytometry from unexposed or Schistosoma exposed mice). (c) Flow cytometry and quantification of the two CD45 ${ }^{+}$TSP-1 ${ }^{+}$populations ' $A$ ' and ' $B$ ' (as in Fig. 1c; $n=3$ /group; $t$-test, NS =non-significant). (d) Representative immunostaining for TSP-1 and Mac3 (macrophage marker), and quantification of the volume fraction of TSP-1 ${ }^{+}$Mac3 ${ }^{+}$cells in the adventitia of vessels by stereology (asterisk: vessel lumen; arrows: representative positive double-stained cells; scale bars: $100 \mu \mathrm{m} ; n=6$ mice/group; $t$-test). (Mean \pm s.d. plotted; $P$ values: ${ }^{\star} P<0.05, \mathrm{NS}=$ non-significant; IP/IV: intraperitoneal/intravenous $S$. mansoni eggs). 
a
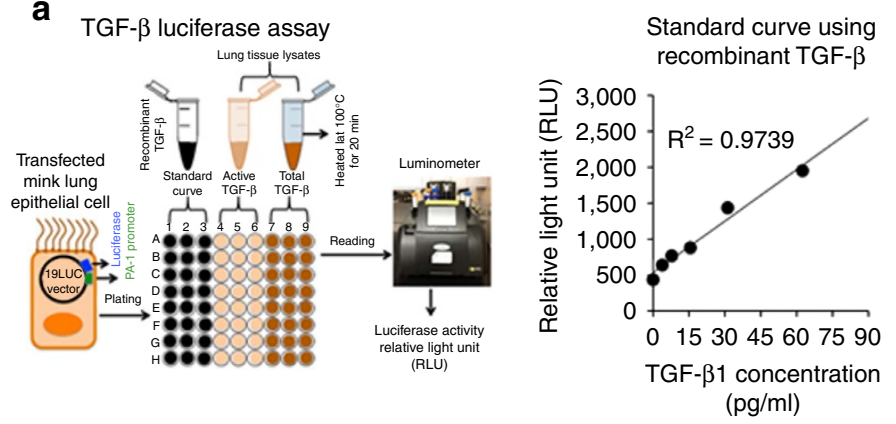

b
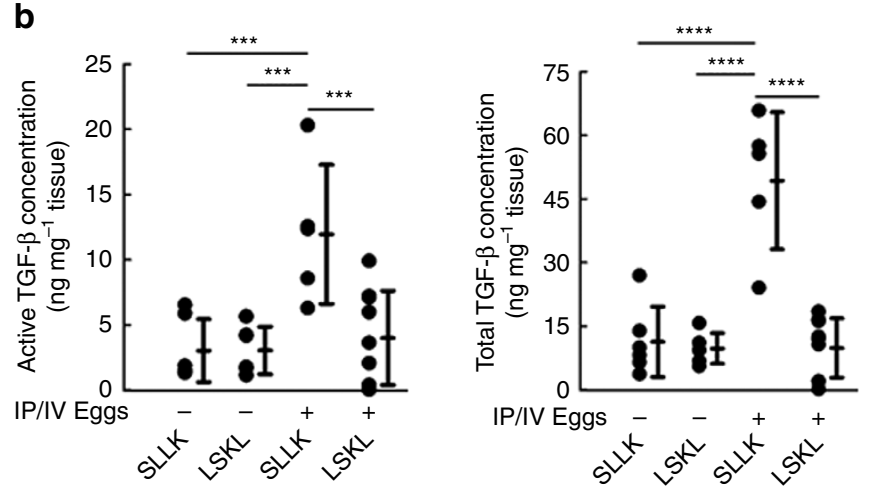
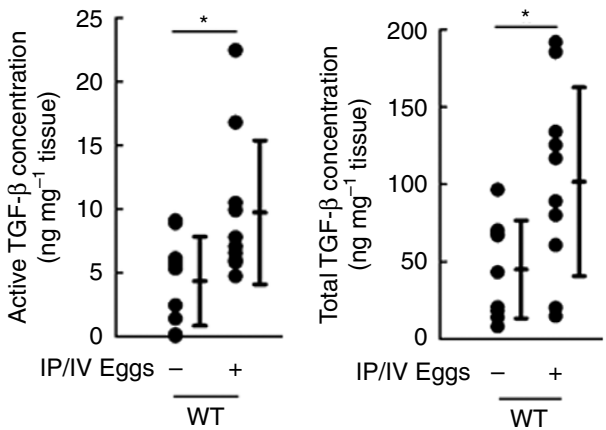

c

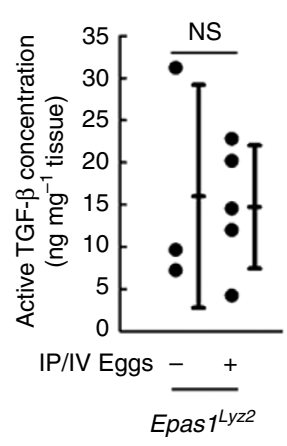

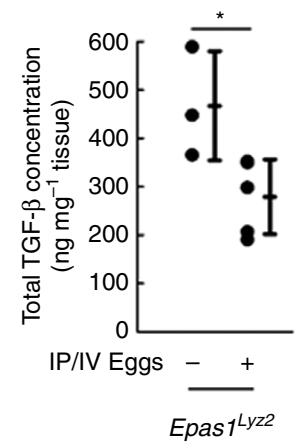

Figure 4 | Assessment of active and total TGF- $\boldsymbol{\beta}$ in whole-lung lysates using a cell-based reporter assay. (a) The experimental scheme and standard curve of luciferase assay using mink lung epithelial cells (MLECS) transfected with PAI-1 promoter fused to firefly luciferase reporter gene, using recombinant TGF- $\beta 1$ to correlate luciferase activity with TGF- $\beta$ concentration, and quantification of the concentration of active and total (by heat treating the sample) TGF- $\beta$ in whole-lung lysates of wild-type mice unexposed or Schistosoma-exposed $(n=9,10 ; 9$ and 10 mice/group, respectively; $t$-test). (b) Concentration of active and total TGF- $\beta$ in whole-lung lysates from WT mice unexposed or Schistosoma-exposed, and treated with LSKL or SLLK ( $n=6$, $6,5,9 ; 6,6,5$ and 9 mice/group, respectively; analysis of variance (ANOVA) $P<0.001$ for both active and total concentrations, with post hoc Tukey tests shown). (c) Concentration of active and total TGF- $\beta$ from whole-lung lysates from Epas $f^{f / / f l} \times$ Lyz2-Cre mice unexposed or Schistosoma-exposed $(n=3,5 ; 3$ and 5 mice/group; $t$-test). (Mean \pm s.d. plotted; $P$ values: ${ }^{\star} P<0.05,{ }^{\star \star \star} P<0.005,{ }^{\star \star \star \star} P<0.001, N S=$ non-significant; IP/IV: intraperitoneal/intravenous S. mansoni eggs).

(Supplementary Fig. 23), reflective of endogenous TGF- $\beta$ signalling. Similar to the blunting effect of LSKL treatment, the concentrations of active and total TGF- $\beta$ in Hif $2 \alpha$ monocyte/ macrophage-deleted (Epas $1^{f l f l} \times$ Lyz2-Cre) mice did not increase following Schistosoma exposure (Fig. 4c). The parallel changes in active and total TGF- $\beta$ are consistent with known positive feedback loops between TGF- $\beta$ signalling and its synthesis ${ }^{35}$.

TSP-1 is also required for hypoxia-induced PH. We then tested the role of TSP-1 in a second murine model of PH, chronic hypoxia exposure. Of note, this exposure utilizes a different trigger than the Th2 inflammation, which drives Schistosoma$\mathrm{PH}^{25}$ : this was evidenced by no change in Il4 or Ill3 mRNA levels with hypoxia exposure, and $I 4^{-/-} I l 13^{-/-}$mice did not have an altered hypoxia-PH phenotype (Supplementary Fig. 24). Despite this different stimulus, whole-lung Thbs1 mRNA and TSP-1 protein levels were significantly higher in hypoxia-exposed mice compared with normoxic control mice, along with increases in both active and total TGF- $\beta$ (Fig. 5a). Similar to the Schistosoma-PH data, hypoxia-exposed mice treated with LSKL were also protected from $\mathrm{PH}$ as measured by RVSP, with suppressed active and total TGF- $\beta$ (Fig. 5b). There were no significant differences in left ventricular systolic pressure, right or left ventricular diastolic pressures, heart rate, or body weight from LSKL treatment (Supplementary Table 3). (We observed little quantitative change in vascular remodelling in this model: Supplementary Fig. 25). Thbs1 ${ }^{-/}$BM transplant into wildtype recipients also prevented hypoxia-induced PH (Fig. 5c).
While these irradiated mice did not develop perivascular fibrosis, their lungs did develop mild parenchymal fibrosis when subsequently challenged by hypoxia (Supplementary Fig. 26).

In another model of human disease, we found significantly higher levels of Thbs 1 mRNA and a strong trend $(P=0.08)$ towards higher levels of TSP-1 protein in whole-lung lysates from newborn calves with chronic hypoxia-induced $\mathrm{PH}$ (Fig. 5d and Supplementary Fig. 27). We also found higher levels of TSP-1 protein in the plasma of adolescent calves with naturally occurring high-altitude PH (Fig. 5e and Supplementary Fig. 28).

Evidence of TSP-1 in human pulmonary vascular disease. TSP-1 in the plasma and skin has been reported to be elevated and correlate with cutaneous disease severity in subjects with scleroderma ${ }^{8,36,37}$, an inflammatory vascular disease, which is often complicated by the development of PAH. To identify the potential relevance of TSP-1 to PAH in this disease, we measured the concentration of TSP-1 in paired plasma samples from seven subjects with scleroderma, drawn before and after development of PAH. There was an average of 4.9 years between the two draws; demographic data are presented in Supplementary Table 4. We observed the concentration of TSP-1 rose significantly following development of PAH (Fig. 6). We also immunostained several $\mathrm{PAH}$ lung specimens, and in two lung specimens identified increased vascular TSP-1 expression (Supplementary Fig. 29). These data are consistent with another recent report that plasma TSP-1 is elevated in patients with $\mathrm{PH}$, and higher levels correlate with poorer prognosis ${ }^{38}$. 
a
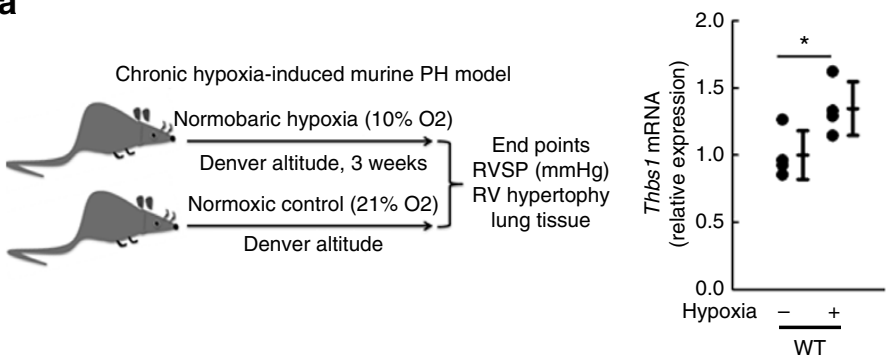

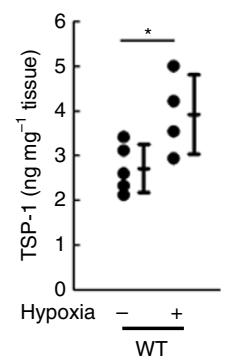

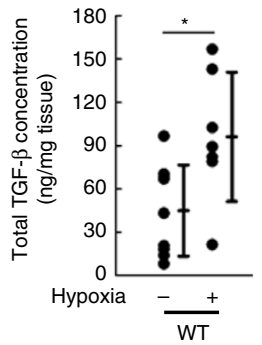

b
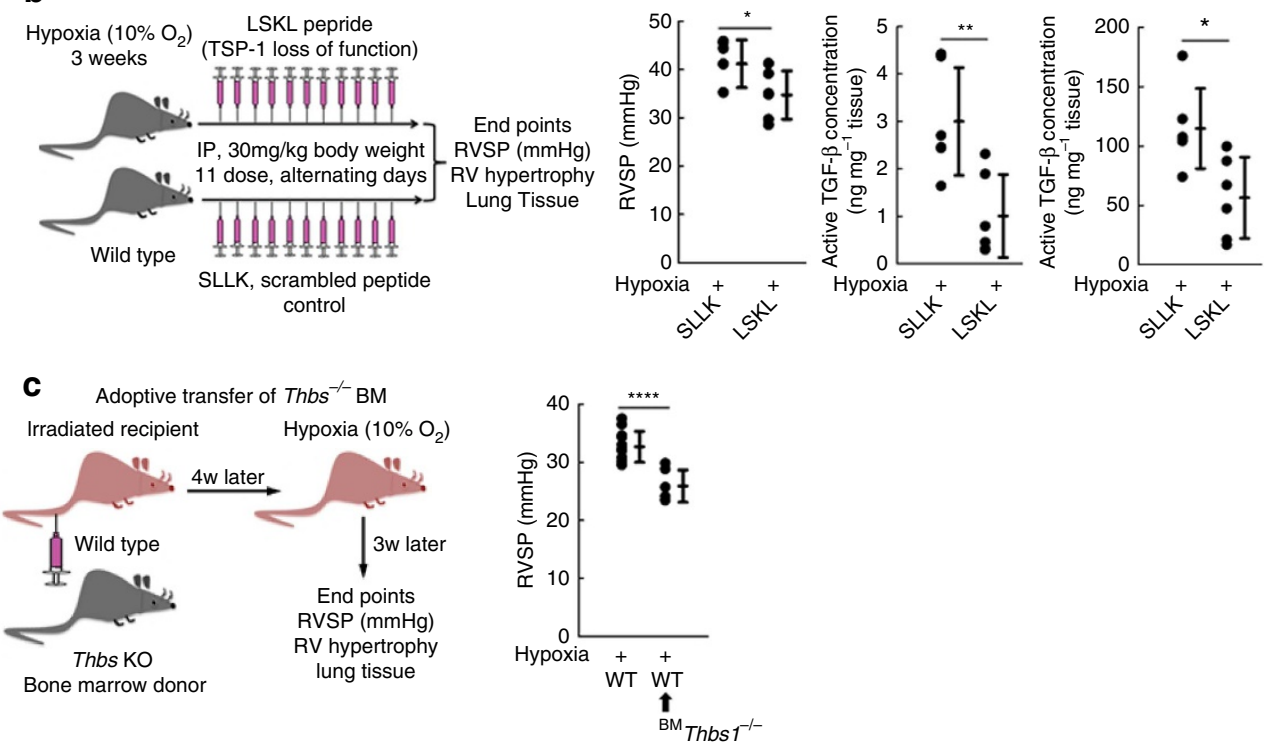

d
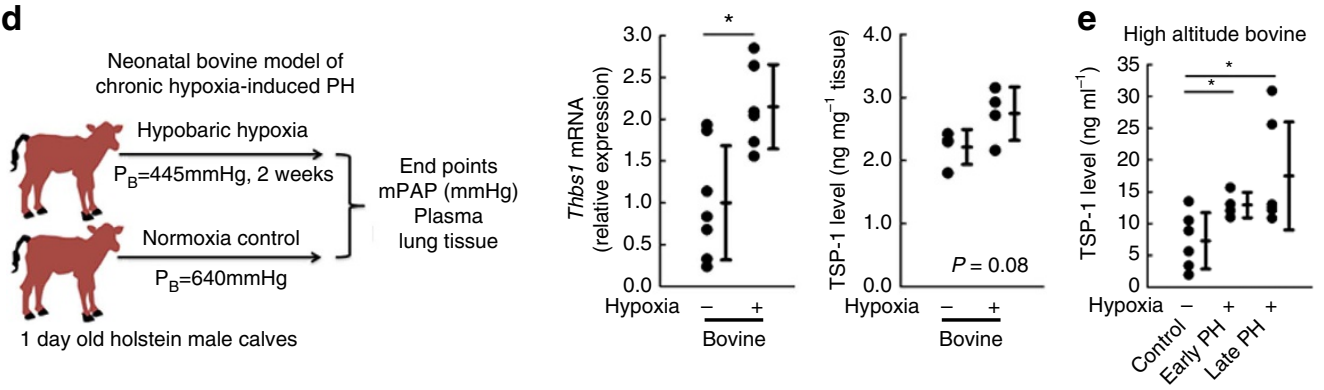

Figure 5 | Assessment of TSP-1 in hypoxia-induced pulmonary hypertension in mice and cows. (a) In mice maintained at normoxia or following 3 weeks

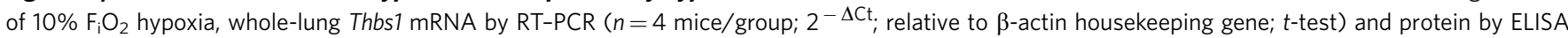
( $n=5$ and 4 mice/group, respectively; $t$-test), and concentrations of active and total TGF- $\beta$ using the MLEC assay $(n=9,7 ; 9$ and 7 mice/group, respectively; $t$-test). (b) RVSP in hypoxia-exposed WT mice treated with LSKL or SLLK ( $n=6$ mice/group; $t$-test), and concentrations of active and total TGF- $\beta$ in whole-lung lysates following SLLK and LSKL treatment using the MLEC assay ( $n=6$ mice/group; $t$-test). (c) RVSP of WT mice or WT recipients of Thbs $1^{-/-}$bone marrow, followed by chronic hypoxia exposure ( $n=13$ and 6 mice/group, respectively; $t$-test). (d) Thbs1 mRNA transcript and TSP-1 protein level in newborn cows exposed to 2 weeks of normoxia or hypobaric hypoxia $(n=7,6 ; 4$ and 4 animals/group, respectively; $2-\Delta C$ t; relative to HPRT housekeeping gene; $t$-test). (e) TSP-1 protein concentration by ELISA in high altitude controls and matched early and late PH adolescent bovine plasma samples ( $n=6,4$ and 6 animals/group, respectively; $t$-test). (Mean \pm s.d. plotted; $P$ values: ${ }^{\star} P<0.05 ;{ }^{\star \star} P<0.01 ;{ }^{\star \star \star} P<0.005,{ }^{\star \star \star \star} P<0.001$ ).

\section{Discussion}

We observed TSP-1 blockade protected against TGF- $\beta$-mediated pulmonary vascular disease, due to both Schistosoma and chronic hypoxia exposure (Fig. 7). In Schistosoma-exposed mice, the pathologic TSP-1 largely originated from Th2-recruited, BMderived $\mathrm{Ly} 6 \mathrm{C}^{+}$monocytes, a cellular source also implicated in other vascular diseases ${ }^{39}$. The significance of these data is reinforced by elevated plasma levels of TSP-1 in patients with scleroderma-associated PAH.

Our findings regarding the necessity for pathologic TGF- $\beta$ activation tie into our previous observations of increased canonical TGF- $\beta$ signalling in the pulmonary vasculature of mice with experimental Schistosoma-PH and autopsy specimens from subjects who died of Schistosoma-PAH as assessed by immunostaining for phospho-Smad2/3, relative to control specimens ${ }^{3}$. (We have not found a difference in BMPR2 pathway signalling via phospho-Smad1/5/8 in Schistosoma-exposed mice ${ }^{25}$ ). Similar to the observed protective effect on Schistosoma-PH resulting from TSP- 1 blockade and consequent inhibition of TGF- $\beta$ activation, we have also found that targeting the TGF- $\beta$ ligand itself, its receptor ALK5/TGF- $\beta$-R1, and the intracellular signalling mediator Smad3 also protected against Schistosoma- $\mathrm{PH}^{3}$. 

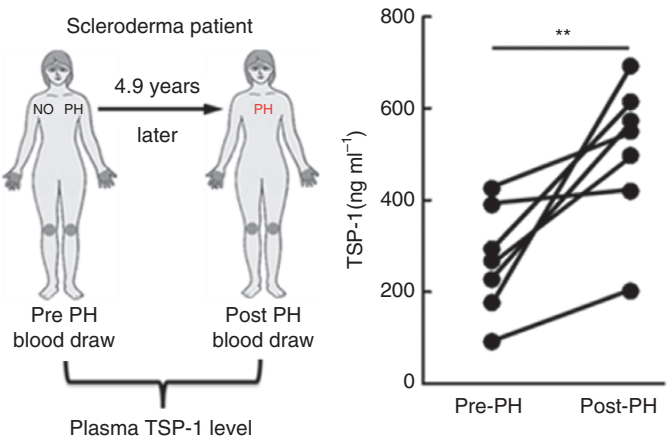

Figure 6 | Assessment of plasma TSP-1 in subjects with sclerodermaassociated disease. Plasma concentration of TSP-1 in scleroderma subjects before and after development of PAH (mean delay $=4.9$ years; $n=7$ subjects; paired $t$-test; $P$ value: $\left.{ }^{\star \star} P<0.01\right)$.

Although TGF- $\beta$ may be activated by different mechanisms in vivo ${ }^{10}$, our data support that TSP-1 appears to underlie the pathologic activation of TGF- $\beta$ in hypoxic and Schistosoma-PH. We did not find a role for TSP-2 in this disease, although TSP-2 can be released by fibroblasts following injury and may contribute to suppressed tissue repair-albeit by a different mechanism than TGF- $\beta$ activation, since TSP- 2 does not have the canonical KRFK motif for TSP-mediated activation ${ }^{40,41}$.

Under normal conditions, TSP- 1 is present at a low concentration, and increases in conditions associated with tissue damage and inflammation ${ }^{42,43}$. TSP-1 has been reported to bind to damaged blood vessel walls and itself can act as a chemoattractant in the recruitment of monocytes ${ }^{42,44}$. Our studies indicate the key role of TSP-1 produced by Ly6C bonemarrow derived cells in the activation of TGF- $\beta 1$ and PH caused by $S$. mansoni infection. Two prior translational studies regarding the role of TSP-1 in PH reported whole-animal genetic ablation is protective in the chronic hypoxia model ${ }^{18,19}$; the interpretation of these findings is confounded by the underlying lung phenotype of emphysema. This phenotype is likely caused by the lack of TGF- $\beta$ activation by TSP-1 (TGF- $\beta$ signalling is necessary for vascular development $\mathrm{t}^{45}$ ) and $\mathrm{PH}$ due to loss of vascular cross-sectional area, as well as altered alternative modes for TGF- $\beta$ activation. This developmental defect may result in a baseline shift in the lung structure, including matrix composition. Moreover, these prior studies also did not elucidate the biologic mechanisms for the role of TSP-1, as this large multimeric protein interacts with other proteins including CD36 and CD47. Such functions could occur in parallel with TGF- $\beta$ activation. One study suggested the effect could be mediated by $\mathrm{CD} 47$ regulating reactive oxygen species production, as anti-CD47 was effective in preventing $\mathrm{PH}$ in monocrotaline-treated rats ${ }^{18}$. CD47 also is known to regulate nitric oxide production, which could affect pulmonary vascular tone ${ }^{46}$, while CD47 null mice have increased expression of TSP-1 and TGF- $\beta$ signalling ${ }^{16}$. Another recent study suggested TSP-1 signalling via $\mathrm{CD} 47$ may regulate the expression of $\mathrm{cMyc}$ and endothelin- 1 as alternate drivers of $\mathrm{PH}^{21}$. Since we were able to block the activation of TGF- $\beta$ by intraperitoneally-injected LSKL peptide and used BM transplantation to overcome the baseline phenotype of Thbs1 null mice, we uncovered a direct role for TSP-1 in the activation of TGF- $\beta$ and the pulmonary hypertensive phenotype due S. mansoni. We did not observe a significant cardiopulmonary phenotype of TSP-1 blockade or deficient $\mathrm{BM}$ in the otherwise untreated adult mouse, suggesting TSP-1 may not have a major role in homeostatic TGF- $\beta$ signalling in the adult lung.

Consistent with prior reports, we also found TSP-1 expression in monocytes to be increased by hypoxia stimulation ${ }^{17,18,47}$, at

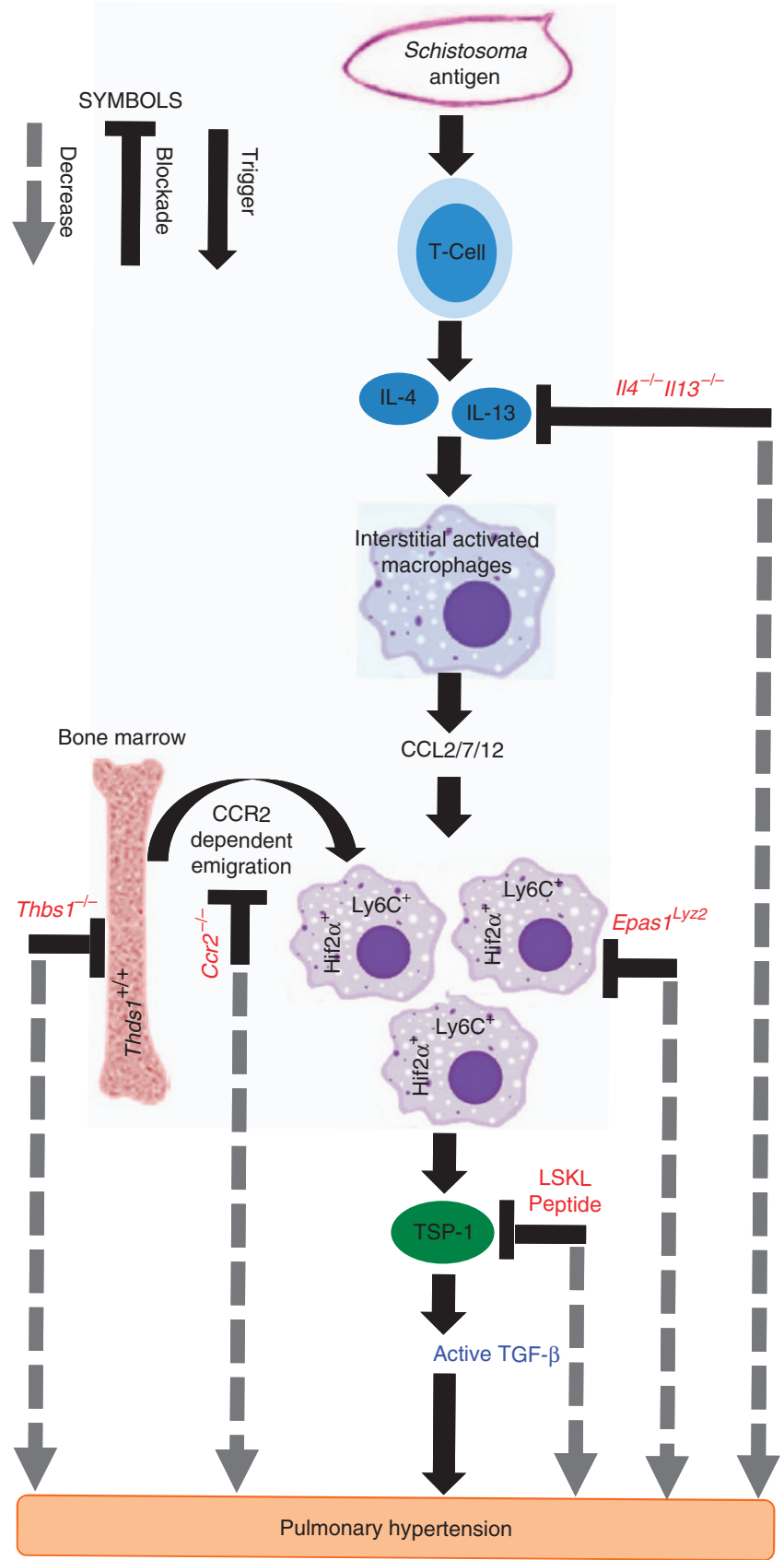

Figure 7 | Overall signalling pathways and intervention approach. Schematic of signalling pathways linking activation of immune cells by Schistosoma exposure with TGF- $\beta$ activation by TSP-1, and subsequent vascular remodelling and $\mathrm{PH}$. Schistosoma exposure leads to Th2 inflammation and release of the cytokines IL-4 and IL-13. These cause activation of interstitial or tissue macrophages, which release CCL2, CCL7 and CCL12. These ligands promote recruitment via CCR2 of bone marrowderived $\mathrm{Ly}_{\mathrm{CC}}{ }^{+}$monocytes into the adventitial space of the lung vasculature, where they bring in TSP-1 (the expression of which is Hif $2 \alpha-$ dependent) to locally activate TGF- $\beta$. Active TGF- $\beta$ then results in remodelling of the pulmonary artery vessel cells, resulting in $\mathrm{PH}$. In red are identified systematic interventions that block causal steps and protect against $\mathrm{PH}$ in these experimental models.

least in part via HIF $2 \alpha^{17}$. However, we also observed whole-lung TSP-1 to be suppressed in HIF $1 \alpha$-deficiency as well. As HIF1 is reported to not bind to HREs in the Thbs 1 promoter ${ }^{17}$, the mechanism for HIF1-regulation of TSP-1 may be mediated by 
blocking monocyte activation, a process which is dependent on glycolysis and HIF1 (refs 48,49). Another possible explanation for the requirement of both Hifs is that HIf1 $\alpha$ may transcriptionally activate a factor that forms a transcriptional activation complex with Hif $2 \alpha$ in the Thbs 1 promoter. It should also be considered that LysM/Lyz2 is expressed by some but not all monocyte/ macrophage populations in Schistosoma ${ }^{50}$, so there may be heterogeneity of gene ablation by Cre recombinase resulting in ony partial downregulation of TSP-1 in these mice. Moreover, there may be additional regulators of TSP-1 expression, such as PPAR- $\gamma$ signalling or reactive oxygen species, both of which are modulated in $\mathrm{PH}^{47,51}$.

We observed that the increased TSP-1 expression largely originated from $\mathrm{BM}$-derived $\mathrm{Ly}_{6 \mathrm{C}} \mathrm{C}^{+}$monocytes, mechanistically supported by higher expression of monocyte CCR2 and its recruiting ligands after Schistosoma exposure; moreover, transplantation of $\mathrm{Ly}_{6 \mathrm{C}}{ }^{+}$cells deficient in CCR2 expression blocked the $\mathrm{PH}$ phenotype seen with transplantation of wild-type cells. This observation is in accordance with reports that activated monocytes can synthesize and secrete TSP-1 (ref. 29). We observed $\mathrm{Ly}_{6} \mathrm{C}^{+}$monocytes home to the adventitial space of remodelled vessels, which allows for spatially localized TSP-1mediated TGF- $\beta$ activation driving the vascular disease. The human equivalent of $\mathrm{Ly} 6 \mathrm{C}^{+}$monocytes, which have a circulating patrolling function responding to sites of inflammation, are $\mathrm{CD} 14^{+}$or 'classical' monocytes ${ }^{52,53}$. Mac3, also called CD107b and lysosome-associated membrane protein 2 (LAMP-2), is a marker of monocyte/macrophage lysosomes (although is present in lysosomes in other tissues as well) and is present in both mice and human cells ${ }^{54}$. Although likely relevant in the pathogenesis of experimental $\mathrm{PH}$, the contribution of monocytes and macrophages to clinical human PAH remains unknown. Despite that other cells can synthesize TSP-1 including epithelial cells and platelets, the finding that the $\mathrm{PH}$ phenotype is dependent on TSP-1 $1^{+}$monocytes specifically argues against a significant role for alternative sources, and reinforces the highly compartment specific function of TSP-1 in the adventitial space. Similarly, TSP-1 may participate in the parenchymal fibrosis in irradiated and hypoxia-challenged mice, but TSP-1 deficiency in the $\mathrm{BM}$ was adequate to protect against hypoxia-induced $\mathrm{PH}$ and overcame a potential pro- $\mathrm{PH}$ effect of irradiation-induced fibrosis.

Our data are supported by a report that in hepatic Schistosoma disease depletion of $\mathrm{Ly} \mathrm{C}^{+}$cells suppresses fibrosis ${ }^{55}$. In both hepatic and pulmonary schistosomiasis, the primary function of these Th2-recruited cells is likely degradation and clearance of parasite antigens. Localized TGF- $\beta$ activation by these cells, via TSP- 1 expression, may contribute to negative feedback loops to prevent over-exuberant inflammation ${ }^{56}$. In the lung, apparently this function can also have the unintended consequence of inducing pulmonary vascular disease, which results in Schistosoma-induced PH. Remarkably, similar mechanisms of pathologic TGF- $\beta$ activation may underlie other non-infectious forms of $\mathrm{PAH}$, such as that due to hypoxia and autoimmune disease, suggesting a shared downstream signalling pathway.

Our observation of increased TSP-1 in the plasma of scleroderma patients following the development of $\mathrm{PAH}$ corroborates prior studies reporting greater TSP-1 protein levels in the lung tissue and pulmonary vasculature, specifically of patients with different forms of $\mathrm{PAH}$, including sclerodermaassociated disease ${ }^{17,18,57}$, and the recent report of higher plasma levels of TSP-1 in patients with more severe PH and decreased survival ${ }^{38}$. In addition, the serum concentration of TGF- $\beta 1$ has also been reported to be increased in Schistosoma$\mathrm{PAH}^{58}$. It would be ideal in the future to determine if plasma
TSP-1 is also elevated in Schistosoma-PAH subjects. Our present work did not address whether delayed TSP-1 blockade reverses established $\mathrm{PH}$ disease. It is conceivable that the TSP- 1 activation of TGF- $\beta$ may trigger early disease pathogenesis but be dispensable later in disease given selfamplifying effects of TGF- $\beta$ signalling.

We did not find evidence of either over-exuberant inflammation or immunocompromise following TSP-1 blockade, suggesting that targeting TSP-1 may precisely block the pathologic activation of TGF- $\beta$ in its specific compartment, without more broadly altering the homeostatic functions of TGF- $\beta$. In Schistosoma-induced disease specifically, blocking TSP-1 may be a more feasible approach than generalized inhibition of Th2 immunity, which could leave the host susceptible to uncontrolled infection. However, it has been reported that, in patients with late-stage $\mathrm{PAH}$, praziquantel is no longer effective at reversing the disease course. This apparent irreversibility of Schistosoma-PAH may derive from self-amplifying feedback of TGF- $\beta$ signalling. Moreover, recent studies reported that patients die without evidence of ongoing egg embolism ${ }^{59-61}$. This chronic sequelae of parasitic infection is in contrast to the more acute Schistosoma mouse model, in which praziquantel blocks egg embolization and ameliorates the exposure to Schistosoma antigen and $\mathrm{PH}$ phenotype ${ }^{62}$.

In summary, we observed that blockade of TSP-1 protects against TGF- $\beta$-mediated pulmonary vascular remodelling due to Schistosoma and hypoxia exposures. Our study underscores potential molecular targets in Schistosoma-induced and other inflammatory forms of human PAH. Direct blockade of TGF- $\beta$ signalling is a major therapeutic challenge due to its ubiquitous nature and localized signalling effects: targeting the pathologic activation of TGF- $\beta$, such as in patients with Schistosomaassociated PAH or with scleroderma at risk for developing scleroderma-associated $\mathrm{PAH}$, holds promise as a potentially safer approach.

\section{Methods}

Animals. C57BL6/J background wild-type and Thbs $1^{-1-}$ mice were purchased from Jackson laboratories (Stock Nos.: 000664 and Stock No: 006141, respectively). Epas $1^{f l / f l} \times$ Lyz2-Cre and Hifla ${ }^{f l / f l} \times$ Lyz2-Cre mice were kindly provided by Dr Holger Eltzschig (University of Colorado Denver). Ccr2 ${ }^{-}$mice were provided by Dr William Janssen (National Jewish Health, Denver). Age- and gendermatched mice in each group were used, and all experiments were performed in a coded format, with the investigators lacking knowledge of the specific experimental group identifiers before final data reporting. Mice were used between 6 and 8 weeks of age. All mice were preserved and housed under specific pathogen-free conditions in an American Association for the Accreditation of Laboratory Animal Careapproved facility of University of Colorado.

The neonatal calf model of severe chronic hypoxia-induced $\mathrm{PH}$ has been described previously 63,64 . Briefly, one day-old male Holstein calves were exposed to hypobaric hypoxia $\left(P_{\mathrm{B}}=445 \mathrm{~mm} \mathrm{Hg}\right)$ for 2 weeks, while age-matched controls were kept at ambient altitude $\left(P_{\mathrm{B}}=640 \mathrm{~mm} \mathrm{Hg}\right)$. The calves were killed by overdose of sodium pentobarbital ( $160 \mathrm{mg} \mathrm{kg}^{-1}$ body weight).

For the adolescent bovine model, yearling male Angus beef calves born and raised at high elevation were used as a natural animal model of chronic and progressive hypoxia-induced PH. Calves $(n=220)$ were born and raised at $2,200 \mathrm{~m}$ (John E. Rouse-Colorado State University Beef Improvement Center, Encampment, WY). Pulmonary arterial pressures were measured by right heart catheterization via the external jugular vein using standardized procedures ${ }^{65}$ and blood samples collected at weaning, age 6-8 months. At this time two groups of bull calves with the lowest and highest mean PA pressures, were selected for follow-up as control and early $\mathrm{PH}$ groups, respectively. Animals were maintained at the ranch under standard feed and housing conditions. Pulmonary arterial pressure test and blood collection were repeated at age 12-13 months. Blood samples were stabilized in K-EDTA vacutainer tubes (Becton-Dickinson catalog \#368589) and stored on ice until processed. Within $2 \mathrm{~h}$ of blood collection, plasma was separated by centrifugation, aliquoted and flash frozen.

Schistosoma mansoni eggs exposure. Schistosoma mansoni eggs were harvested from homogenized and purified livers of Swiss-Webster mice infected with cercariae, provided by the Biomedical Research Institute (Rockville, MD). Similar to report in our previous publications ${ }^{3,25}$, experimental mice were intraperitoneally 
sensitized to $240 \mathrm{~S}$. mansoni eggs/gram body weight, and then intravenously challenged two weeks later with $175 \mathrm{~S}$. mansoni eggs/gram body weight. Control mice were unexposed to $S$. mansoni eggs.

Chronic hypoxia exposure. For hypoxia exposure, we placed mice in a chamber with $10 \% \mathrm{FiO}_{2}$ at Denver altitude for three weeks. The partial pressure of oxygen was regulated by a ProOx 110 (Biospherix, Parish, NY) oxygen sensor and feedback loop regulating the flow of nitrogen gas out of a tank and into the chamber, within which the gas is mixed with a fan.

BM transplantation. To perform BM transplantation, we used a cesium irradiator (provided by the University of Colorado core facility). C57BL/6 recipient wild-type and Thbs $1^{-1-}$ recipient mice were irradiated with 10 Graey split into two fractions $4 \mathrm{~h}$ apart, before intravenous injection with $>1.5 \times 10^{6} \mathrm{BM}$ cells isolated as described previously ${ }^{66}$ from Thbs $1^{-}-$and wild-type donor mice. The irradiated BM recipient mice were kept on trimethoprim chow for 4 weeks, followed by return to normal diet and then the above protocol of Schistosoma or hypoxia exposures.

Pharmacologic treatments. The soluble peptides LSKL and SLLK (GenScript, NJ, USA) were reconstituted in PBS. These peptides were administered intraperitoneally $30 \mathrm{mg} \mathrm{kg}^{-1}$ per every alternate day from day 13 to day 21 for S. mansoni egg-exposed mice and from day $0-21$ for hypoxia-exposed mice. LSKL treatment of Schistosoma mice started at the time of intravenous egg augmentation, as we believe the intravenous eggs trigger an immunologic cascade starting with pulmonary dendritic cell uptake of antigen and presentation to sensitized CD4 T cells and Th2 immunity. Control mice received the same dose of scrambled peptide. The quantity and schedule of the treatment was based on prior reports in other disease models ${ }^{30}$. We performed an initial pilot study that found no protection with a lower dose of $3 \mathrm{mg} \mathrm{kg}^{-1}$ but protection with a dose of $30 \mathrm{mg} \mathrm{kg}^{-1}$ (Supplementary Fig. 30).

Experimental PH and RV hypertrophy measurement. To measure RVSP, mice were sedated using intraperitoneal ketamine-xylazine, tracheotomy performed, and mechanical ventilation initiated at $6 \mathrm{cc} \mathrm{kg}^{-1}$ through the transtracheal catheter. We then used sharp dissection to open the abdomen and diaphragm to place a 1 French pressure-volume catheter (Millar PVR-1035, Millar ADInstruments, Houston, TX) directly into the RV and then LV chambers through the free walls, as previously described ${ }^{3,24,25}$. After completing haemodynamic measurements, the blood from the lungs were flushed with PBS, the right bronchus sutured and the left lung inflated with $1 \%$ low melt agarose for formalin fixation and parafin embedding for histology, and the right lung split for snap freezing for protein studies or placed into RNAlater (Ambion or Life Technologies, Carlsbad, CA) for RNA quantification. The right ventricle free wall was removed from the left ventricle and the septum, and weighed relative to the septum and left ventricle to determine the Fulton index.

RNA and protein assessment of mouse tissue. mRNA was retrieved from RNA later-preserved mouse whole-lung tissue by Qiagen RNAeasy kit (Hilden, Germany). mRNA expression levels quantified using an Illumina (San Diego, CA) HiSeq 2000 RNA sequencing (RNA-seq) system and analysed using CASAVA (Illumina), with the results expressed as reads per kilobase of exon model per million mapped reads (RPKM). Further details of the RNA-seq protocol including sample preparation, RNA sequencing protocol, and post-processing sequence reconstruction were previously reported ${ }^{67}$. These RNA-seq data presented have been deposited in NCBI's Gene Expression Omnibus and are accessible through GEO series accession number GSE49116.

mRNA was also retrieved from sorted alveolar and tissue macrophages from Schistosoma-exposed and unexposed mice (see flow cytometry details below), and pooled from five mice in each group for whole-transcriptome quantification and analysis, performed at the National Jewish Health (Denver CO) Genomics Facility using the Ion Proton NGS platform (Life Technologies, Carlsbad, CA). A Kapa Stranded mRNA-Seq kit (Kapa Biosystems, Wilmington, MA) was used to generate whole-transcriptome libraries for sequencing, using a workflow that included polyA mRNA isolation, complementary DNA synthesis, adaptor ligation, amplification, bead templating and validation. After sequencing the fastq files were uploaded to Galaxy online (http://usegalaxy.org), and the RNA-seq reads were mapped to the mouse mm10 genome using Bowtie-Tophat-Cufflinks. Bowtie uses the Burrows-Wheeler transform for alignment, Tophat identifies splice junctions, and Cufflinks assembles and quantifies the transcriptome (15-17). Differences between the groups were expressed as fold change. These RNA-seq data have also been deposited in NCBI's Gene Expression Omnibus and are accessible through GEO series accession number GSE84651.

In addition, we also used reverse transcription polymerase chain reaction (RTPCR) (ABI, CA, USA) to quantify expression of Thbs 1, Pail, Il4 and Ill3 mRNA transcript in sorted cells, chronic hypoxia exposed and pharmacological peptide treated mice. RT-PCR was performed in triplicates for each gene and each sample. To calculate relative transcript quantities, the $2^{-\Delta \mathrm{Ct}}$ method was used with $\beta$-actin and glyceraldehyde-3-phosphate dehydrogenase $(G a p d h)$ as endogenous reference genes.

For protein quantification, a sample of frozen right lung tissue was macerated and sonicated in RIPA buffer containing anti-proteases, and protein concentration was determined by Bradford assay (BioRad). Protein from mouse whole-lung lysates was used for enzyme-linked immunosorbent assay (ELISA) to determine the concentration of specific proteins in samples using the kits in Supplementary Table 5 in the online data supplement.

Immunostaining was performed on formalin-fixed and paraffin-embedded mouse lung tissue using the reagents in Supplementary Table 6 in the online data supplement.

Flow cytometry assessment of mouse tissue. Mice were challenged with $S$. mansoni eggs or hypoxia as per our established protocol. Three days after intravenous egg augmentation, the mouse lungs were perfused with sterile PBS and digested for flow cytometry analysis as previously reported ${ }^{25}$. Briefly, the lungs were digested using $1 \mathrm{mg} \mathrm{ml}^{-1}$ of collagenase (Fisher Bioreagents) dissolved in RPMI (Mediatech). The digested samples were incubated at $37^{\circ} \mathrm{C}$ for $30 \mathrm{~min}$ and the tissue was disrupted by vigorous pipetting at least $50 \times$ using a $1 \mathrm{ml}$ pasture pipet. The filtered cell suspension using $40 \mu \mathrm{M}$ mesh cell strainer (Biologix group) followed by centrifugation at 1,200 r.p.m. for $5 \mathrm{~min}$ and the pellet was resuspended into flow wash buffer (5\% BSA in PBS/EDTA). The cells were then enumerated using a Neubauer chamber. The samples were distributed into $10^{6}$ cells per $100 \mu \mathrm{l}$ of flow wash buffer. Blocking of non-specific Fc receptor-mediated antibody binding was performed (CD16/CD32 BD Pharmingen) and the cells were initially stained intracellularly and extracellularly for TSP-1 using fluorochrome conjugated antibodies in a concentration of $1 \mathrm{\mu g} \mathrm{ml}^{-1}$ (Supplementary Table 7 in the online data supplement). The samples were incubated at $4{ }^{\circ} \mathrm{C}$ in the dark for $30 \mathrm{~min}$. The cells were then centrifuged, the supernatant discarded and the cells were fixed using a $1 \%$ paraformaldehyde/ $3 \%$ sucrose $\mathrm{pH} 7.2$ solution. The cells were treated with a final concentration of $0.5 \%$ saponin and stained intracellularly for TSP-1 using fluorochrome conjugated antibodies at a concentration of $2 \mu \mathrm{g} \mathrm{ml}^{-1}$ and incubated at $4{ }^{\circ} \mathrm{C}$ in the dark for $30 \mathrm{~min}$ (Supplementary Table 7 in the online data supplement). The cells were then washed and ready for analysis. As a control, all samples had an intracellular unstained aliquot that was stained extracellularly only. The data was acquired using a BD LSRII flow cytometer with a BD Facs DIVA software. Compensation was calculated by the DIVA software based on compensation controls for each fluochrome used in the experiment. The raw data was then analysed using FlowJo Sofware, version 7.6 (Tree Star, Inc). A gating strategy was designed to identify the different populations of interest in the study (see the results section). To do RT-PCR on the sorted cells we used multiple panels of fluorochrome labelled antibodies to identify TSP-1 expression in recruited $\left(\mathrm{CD}^{+} 4^{+}, \mathrm{MerTK}^{+}, \mathrm{CD}_{11 \mathrm{~b}}{ }^{+}, \mathrm{CD} 1 \mathrm{cc}^{-}\right)$,

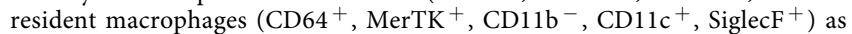
well as in monocytes (CD64 intermediate, Ly6 $\mathrm{C}^{+}$). All flow cytometry experiments were carried out using a LSRII (BD Biosciences) instrument from the Clinical Immunology Flow Cytometry/Cell Sorting facility located at the University of Colorado Anschutz Medical Campus.

Active and total TGF-ק1 quantification. The quantity of active and tota TGF- $\beta 1$ in the whole lung was assessed using lung tissue lysates added to a cellular assay using mink lung epithelial cells (MLEC) transfected with a human PAI-1 promoter fused to the firefly luciferase reporter gene to detect active TGF- $\beta$ (kindly provided by Dr Daniel Rifkin, NYU ${ }^{31}$ ). The functionality of these cells was confirmed by the linear production of luciferase by TGF- $\beta 1$ treatment (Fig. 4a). The whole-lung lysates were heated at $100{ }^{\circ} \mathrm{C}$ for $20 \mathrm{~min}$ to quantify total TGF- $\beta$. The luciferase activity was recorded as relative light units. Relative light unit values were converted to TGF- $\beta$ activity ( $\mathrm{pg} \mathrm{ml} \mathrm{m}^{-1}$ ) using a standard curve generated using serial dilution of recombinant TGF- $\beta 1$.

Media thickness assessment. Quantification of media thickness in mouse lung tissue was determined as previously described ${ }^{3,24,25}$. Briefly, 10 to 12 images of vessels at $40 \times$ magnification were randomly acquired from masked paraffinembedded samples immunofluorescence stained for $\alpha$-smooth muscle actin, as described above. Image processing software (Image Pro Plus v4.5.1, Media Cybernetics, Bethesda, MD) was used to identify cross-sectional areas contained by the external perimeter of the media and the internal perimeter of the media. The radius $r_{i}$ for each of the two vessel layers $i$ enclosing an area $A_{i}$ was calculated using the equation

$$
r_{i}=\sqrt{A_{i} / \pi}
$$

The fractional thicknesses of the media was calculated as the difference between the two radii, and expressed as a fraction of the external media radius.

Granuloma volume assessment. Peri-egg granuloma volumes were measured using the optical rotator stereologic method ${ }^{3,24,25,68}$. Briefly, paraffin-embedded 
tissue was stained with haematoxylin and eosin, and 8-10 images of granulomas with single visible ova were acquired for each sample. The rotator method for object volume estimation was then applied using the ova as the central reference point with image processing software (Image Pro Plus v4.5.1, Media Cybernetics, Bethesda, MD).

Egg burden quantification. The number of $S$. mansoni eggs present in the mouse lung tissue was determined as previously described ${ }^{69}$. Briefly, 20 to $30 \mathrm{mg}$ of frozen right lung tissue was digested in $4 \%$ potassium hydroxide $(\mathrm{KOH})$ for $18 \mathrm{~h}$ at $33^{\circ} \mathrm{C}$ using shaker incubator, and the number of eggs present in aliquots of the digest was counted.

\section{Localization of signalling molecules and fibrosis assessment. Analysis by} stereology was used to calculate the fraction of adventitia volume occupied by cells staining positive for both Mac3 and TSP-1 cells ${ }^{70}$. Eight to 10 images of vessels were acquired from each sample. Image processing software (Metamorph, Molecular Devices LLC, Sunnyvale, CA) was used to threshold each signal for positive cells, and the same pixels, which thresholded positive for both Mac3 and TSP-1 signals were determined. This was superimposed on a grid, and the number of double-positive pixels which intersected with the grid, divided by the total number of grid points within the adventitia, was calculated as the fraction of volume of adventitia which stained positive for both markers $^{70}$. The same method was used to identify the volume fraction of picrosirus polarization-positive material to identify fibrosis. The adventitia was identified as the space outside the media and inside any surrounding airways or alveoli.

Pulmonary function testing. Pulmonary function was analysed using a flexiVent (Scireq, Montreal, Canada). Mice were anaesthetized with urethane $\left(2.0 \mathrm{~g} \mathrm{~kg}^{-1}\right.$, intraperitoneal) followed by tracheostomy with a blunt bevelled 18-G Luer stub adaptor, and once ventilated ( 150 breaths per $\mathrm{min}, 10 \mathrm{ml} \mathrm{kg}^{-1}$, against $3 \mathrm{~cm} \mathrm{H}_{2} \mathrm{O}$ positive end expiratory pressure), they were paralysed by continuous infusion of succinylcholine chloride $\left(10 \mathrm{mg} \mathrm{kg}^{-1} \mathrm{~min}^{-1}\right.$, intraperitoneally).

Human sample analysis. Banked plasma samples were collected pre and post PAH development in scleroderma patients. The clinical characteristics are presented in Supplementary Table 4 in the online data supplement. Plasma TSP-1 concentration was quantified by ELISA (R\&D Systems, Minneapolis, MN, Catalog \#DTSP10).

Banked PAH lung tissue obtained at the time of lung transplantation and control lung tissue from failed lung donors was obtained from the Pulmonary Hypertension Breakthrough Initiative (PHBI; funded by R24HL123767), and immunostained using the reagents in Supplementary Table 8 in the online data supplement. The following types of tissue were used:

PAH: 3 scleroderma-associated PAH, 2 lupus-associated PAH, 1 congenital heart disease-associated PAH (patent ductus arteriosus), and 1 rheumatoid arthritis-associated PAH.

Control: 5 lung donors, with no known pre-existing lung disease and no identifiable lung disease on histology, all with isolated cerebral injury.

Statistical analysis. ProStat program (version 6, Poly Software International, Pearl River, NY) and SigmaPlot 13.0 were used to perform Statistical analyses. Differences between two groups were assessed with the $t$-test; whereas, for $\geq 3$ groups difference were assessed by the analysis of variance followed by post hoc pairwise multiple comparison testing using the Tukey test. $P$ values $<0.05$ were considered to be statistically significant. Non-normally distributed data was analysed by non-parametric analysis. Of note, Animals Scientific Procedures Act (ASPA) guidelines were followed to achieve robust and reproducible results with power $>90 \%$ by using minimum number of animals per experiment. We did not experience any premature or unexpected animal mortality during Schistosoma or hypoxia exposure, treatment with pharmacological peptide, or irradiation of mice for BM experiments. No mice were prematurely excluded from analysis. Mice were randomized to receive different treatments, such as LSKL or SLLK.

Ethical approval for animal and human studies. The Animal Care and Use Committee at the University of Colorado Denver approved all experimental procedures in rodents. For the bovine models, standard veterinary care was used following institutional guidelines at the Department of Physiology, School of Veterinary Medicine, Colorado State University (Fort Collins, CO), with animal protocols approved by the Colorado State University IACUC. All human studies were approved by the Colorado Multiple Institutional Review Board. Informed consent was obtained from all subjects.

Data availability. Whole-lung mRNA quantification by RNA-seq have been deposited in NCBI's Gene Expression Omnibus and are accessible through GEO series accession number GSE49116. Sorted macrophage mRNA quantification by RNA-seq have been also been deposited and are accessible through GEO series accession number GSE84651. All relevant data are available from the authors.

\section{References}

1. Simonneau, G. et al. Updated clinical classification of pulmonary hypertension. J. Am. Coll. Cardiol. 62, D34-D41 (2013).

2. Tuder, R. M. et al. Relevant issues in the pathology and pathobiology of pulmonary hypertension. J. Am. Coll. Cardiol. 62, D4-12 (2013).

3. Graham, B. B. et al. Transforming growth factor- $\beta$ signaling promotes pulmonary hypertension caused by Schistosoma mansoni. Circulation 128, 1354-1364 (2013).

4. Richter, A. et al. Impaired transforming growth factor-beta signaling in idiopathic pulmonary arterial hypertension. Am. J. Respir. Crit. Care Med. 170, 1340-1348 (2004).

5. Lane, K. B. et al. Heterozygous germline mutations in BMPR2, encoding a TGF-beta receptor, cause familial primary pulmonary hypertension. Nat. Genet. 26, 81-84 (2000).

6. Ma, W. et al. Calpain mediates pulmonary vascular remodeling in rodent models of pulmonary hypertension, and its inhibition attenuates pathologic features of disease. J. Clin. Invest. 121, 4548-4566 (2011).

7. Zaiman, A. L. et al. Role of the TGF-beta/Alk5 signaling pathway in monocrotaline-induced pulmonary hypertension. Am. J. Respir. Crit. Care Med. 177, 896-905 (2008).

8. Rice, L. M. et al. Fresolimumab treatment decreases biomarkers and improves clinical symptoms in systemic sclerosis patients. J. Clin. Invest. 125, 2795-2807 (2015).

9. Lacouture, M. E. et al. Cutaneous keratoacanthomas/squamous cell carcinomas associated with neutralization of transforming growth factor $\beta$ by the monoclonal antibody fresolimumab (GC1008). Cancer Immunol. Immunother 64, 437-446 (2015).

10. Travis, M. A. \& Sheppard, D. TGF- $\beta$ activation and function in immunity. Annu. Rev. Immunol. 32, 51-82 (2014).

11. Robertson, I. B. \& Rifkin, D. B. Unchaining the beast; insights from structura and evolutionary studies on TGF $\beta$ secretion, sequestration, and activation. Cytokine Growth Factor Rev. 24, 355-372 (2013).

12. Crawford, S. E. et al. Thrombospondin-1 is a major activator of TGF-betal in vivo. Cell 93, 1159-1170 (1998).

13. Ribeiro, S. M., Poczatek, M., Schultz-Cherry, S., Villain, M. \& Murphy-Ullrich, J. E The activation sequence of thrombospondin- 1 interacts with the latency-associated peptide to regulate activation of latent transforming growth factor-beta. J. Biol. Chem. 274, 13586-13593 (1999).

14. Morris, D. G. et al. Loss of integrin alpha(v)beta6-mediated TGF-beta activation causes Mmp12-dependent emphysema. Nature 422, 169-173 (2003).

15. Schultz-Cherry, S., Lawler, J. \& Murphy-Ullrich, J. E. The type 1 repeats of thrombospondin 1 activate latent transforming growth factor-beta. J. Biol. Chem. 269, 26783-26788 (1994).

16. Soto-Pantoja, D. R. et al. Thrombospondin-1 and CD47 signaling regulate healing of thermal injury in mice. Matrix Biol. J. Int. Soc. Matrix Biol. 37, 25-34 (2014).

17. Labrousse-Arias, D. et al. HIF- $2 \alpha$-mediated induction of pulmonary thrombospondin-1 contributes to hypoxia-driven vascular remodelling and vasoconstriction. Cardiovasc. Res. 109, 115-130 (2016).

18. Bauer, P. M. et al. Activated CD47 promotes pulmonary arterial hypertension through targeting caveolin-1. Cardiovasc. Res. 93, 682-693 (2012).

19. Ochoa, C. D., Yu, L., Al-Ansari, E., Hales, C. A. \& Quinn, D. A. Thrombospondin-1 null mice are resistant to hypoxia-induced pulmonary hypertension. J. Cardiothorac. Surg. 5, 32 (2010).

20. Resovi, A., Pinessi, D., Chiorino, G. \& Taraboletti, G. Current understanding of the thrombospondin-1 interactome. Matrix Biol. J. Int. Soc. Matrix Biol. 37, 83-91 (2014).

21. Rogers, N. M. et al. TSP1-CD47 signaling is upregulated in clinical pulmonary hypertension and contributes to pulmonary arterial vasculopathy and dysfunction. Cardiovasc. Res. 113, 15-29 (2017).

22. Maloney, J. P. et al. Loss-of-function thrombospondin-1 mutations in familial pulmonary hypertension. Am. J. Physiol. Lung Cell. Mol. Physiol. 302, L541-L554 (2012).

23. Hotez, P. J. et al. Helminth infections: the great neglected tropical diseases. J. Clin. Invest. 118, 1311-1321 (2008).

24. Graham, B. B. et al. Schistosomiasis-induced experimental pulmonary hypertension: role of interleukin-13 signaling. Am. J. Pathol. 177, 1549-1561 (2010).

25. Kumar, R. et al. The causal role of IL-4 and IL-13 in Schistosoma mansoni pulmonary hypertension. Am. J. Respir. Crit. Care Med. 192, 998-1008 (2015)

26. Wilson, M. S. et al. Immunopathology of schistosomiasis. Immunol. Cell Biol. 85, 148-154 (2007). 
27. Nascimento, M. et al. Ly6Chi monocyte recruitment is responsible for Th2 associated host-protective macrophage accumulation in liver inflammation due to schistosomiasis. PLoS Pathog. 10, e1004282 (2014).

28. Arnold, L. et al. Inflammatory monocytes recruited after skeletal muscle injury switch into antiinflammatory macrophages to support myogenesis. J. Exp. Med. 204, 1057-1069 (2007).

29. Jaffe, E. A., Ruggiero, J. T. \& Falcone, D. J. Monocytes and macrophages synthesize and secrete thrombospondin. Blood 65, 79-84 (1985).

30. Lu, A., Miao, M., Schoeb, T. R., Agarwal, A. \& Murphy-Ullrich, J. E. Blockade of TSP1-dependent TGF- $\beta$ activity reduces renal injury and proteinuria in a murine model of diabetic nephropathy. Am. J. Pathol. 178, 2573-2586 (2011).

31. Abe, M. et al. An assay for transforming growth factor-beta using cells transfected with a plasminogen activator inhibitor-1 promoter-luciferase construct. Anal. Biochem. 216, 276-284 (1994).

32. Li, W.-Y. et al. Transforming growth factor-beta3 affects plasminogen activator inhibitor-1 expression in fetal mice and modulates fibroblast-mediated collagen gel contraction. Wound Repair Regen. 14, 516-525 (2006).

33. Kutz, S. M., Hordines, J., McKeown-Longo, P. J. \& Higgins, P. J. TGF-beta1induced PAI-1 gene expression requires MEK activity and cell-to-substrate adhesion. J. Cell Sci. 114, 3905-3914 (2001).

34. Fuchshofer, R., Welge-Lussen, U. \& Lütjen-Drecoll, E. The effect of TGF-beta2 on human trabecular meshwork extracellular proteolytic system. Exp. Eye Res. 77, 757-765 (2003).

35. Van Obberghen-Schilling, E., Roche, N. S., Flanders, K. C., Sporn, M. B. \& Roberts, A. B. Transforming growth factor beta 1 positively regulates its own expression in normal and transformed cells. J. Biol. Chem. 263, 7741-7746 (1988).

36. Rice, L. M. et al. A longitudinal biomarker for the extent of skin disease in patients with diffuse cutaneous systemic sclerosis. Arthritis Rheumatol. 67, 3004-3015 (2015)

37. Macko, R. F. et al. Increased circulating concentrations of the counteradhesive proteins SPARC and thrombospondin-1 in systemic sclerosis (scleroderma). Relationship to platelet and endothelial cell activation. J. Rheumatol. 29, 2565-2570 (2002).

38. Kaiser, R., Frantz, C., Bals, R. \& Wilkens, H. The role of circulating thrombospondin-1 in patients with precapillary pulmonary hypertension. Respir. Res. 17, 96 (2016).

39. Shirai, T. et al. The glycolytic enzyme PKM2 bridges metabolic and inflammatory dysfunction in coronary artery disease. J. Exp. Med. 213, 337-354 (2016).

40. Bancroft, T. et al. Up-regulation of thrombospondin-2 in Akt1-null mice contributes to compromised tissue repair due to abnormalities in fibroblast function. J. Biol. Chem. 290, 409-422 (2015).

41. Daniel, C., Vogelbacher, R., Stief, A., Grigo, C. \& Hugo, C. Long-term gene therapy with thrombospondin 2 inhibits TGF- $\beta$ activation, inflammation and angiogenesis in chronic allograft nephropathy. PLoS ONE 8, e83846 (2013).

42. Liu, Z. et al. Thrombospondin-1 (TSP1) contributes to the development of vascular inflammation by regulating monocytic cell motility in mouse models of abdominal aortic aneurysm. Circ. Res. 117, 129-141 (2015).

43. Krishna, S. M. \& Golledge, J. The role of thrombospondin-1 in cardiovascular health and pathology. Int. J. Cardiol. 168, 692-706 (2013).

44. Mansfield, P. J. \& Suchard, S. J. Thrombospondin promotes chemotaxis and haptotaxis of human peripheral blood monocytes. J. Immunol. 153, 4219-4229 (1994).

45. Goumans, M. J. \& Mummery, C. Functional analysis of the TGF beta receptor/ Smad pathway through gene ablation in mice. Int. J. Dev. Biol. 44, 253-265 (2000).

46. Isenberg, J. S. et al. CD47 is necessary for inhibition of nitric oxide-stimulated vascular cell responses by thrombospondin-1. J. Biol. Chem. 281, 26069-26080 (2006).

47. Green, D. E., Kang, B.-Y., Murphy, T. C. \& Hart, C. M. Peroxisome proliferator-activated receptor gamma $(\operatorname{PPAR} \gamma)$ regulates thrombospondin-1 and Nox4 expression in hypoxia-induced human pulmonary artery smooth muscle cell proliferation. Pulm. Circ. 2, 483-491 (2012).

48. Marsin, A.-S., Bouzin, C., Bertrand, L. \& Hue, L. The stimulation of glycolysis by hypoxia in activated monocytes is mediated by AMP-activated protein kinase and inducible 6-phosphofructo-2-kinase. J. Biol. Chem. 277, 30778 30783 (2002)

49. Shalova, I. N. et al. Human monocytes undergo functional re-programming during sepsis mediated by hypoxia-inducible factor-1 $\alpha$. Immunity 42, 484-498 (2015).

50. Vannella, K. M. et al. Incomplete deletion of IL-4R $\alpha$ by $\operatorname{LysM(Cre)~reveals~}$ distinct subsets of M2 macrophages controlling inflammation and fibrosis in chronic schistosomiasis. PLoS Pathog. 10, e1004372 (2014).

51. Hayashi, H., Sakai, K., Baba, H. \& Sakai, T. Thrombospondin-1 is a novel negative regulator of liver regeneration after partial hepatectomy through transforming growth factor-betal activation in mice. Hepatology 55, 1562-1573 (2012).
52. Lauvau, G., Chorro, L., Spaulding, E. \& Soudja, S. M. Inflammatory monocyte effector mechanisms. Cell Immunol. 291, 32-40 (2014).

53. Shi, C. \& Pamer, E. G. Monocyte recruitment during infection and inflammation. Nat. Rev. Immunol. 11, 762-774 (2011).

54. Eskelinen, E.-L. Roles of LAMP-1 and LAMP-2 in lysosome biogenesis and autophagy. Mol. Aspects Med. 27, 495-502 (2006).

55. Borthwick, L. A. et al. Macrophages are critical to the maintenance of IL-13dependent lung inflammation and fibrosis. Mucosal Immunol. 9, 38-55 (2015).

56. Hams, E., Aviello, G. \& Fallon, P. G. The schistosoma granuloma: friend or foe? Front. Immunol. 4, 89 (2013).

57. Rogers, N. M. et al. Cellular, pharmacological, and biophysical evaluation of explanted lungs from a patient with sickle cell disease and severe pulmonary arterial hypertension. Pulm. Circ. 3, 936-951 (2013).

58. Ferreira, R. C. et al. TGF beta and IL13 in schistosomiasis mansoni associated pulmonary arterial hypertension; a descriptive study with comparative groups. BMC Infect. Dis. 14, 282 (2014).

59. Bandeira, A. P., Mendes, A. A., Santos-Filho, P., Sa, D. T. \& Loureiro, R Clinical efficacy of oral sildenafil in severe pulmonary hypertension in patients with chronic pulmonary schistosomiasis. Circulation 110, 296 (2004).

60. Fernandes, C. J. et al. The role of target therapies in schistosomiasis-associated pulmonary arterial hypertension. Chest 141, 923-928 (2012).

61. Graham, B. B. et al. Significant intrapulmonary Schistosoma egg antigens are not present in schistosomiasis-associated pulmonary hypertension. Pulm. Circ. 1, 456-461 (2011).

62. Crosby, A. et al. Praziquantel reverses pulmonary hypertension and vascular remodeling in murine schistosomiasis. Am. J. Respir. Crit. Care Med. 184, 467-473 (2011).

63. Li, M. et al. Emergence of fibroblasts with a proinflammatory epigenetically altered phenotype in severe hypoxic pulmonary hypertension. J. Immunol. 187, 2711-2722 (2011).

64. Das, M., Burns, N., Wilson, S. J., Zawada, W. M. \& Stenmark, K. R. Hypoxia exposure induces the emergence of fibroblasts lacking replication repressor signals of PKCzeta in the pulmonary artery adventitia. Cardiovasc. Res. 78, 440-448 (2008).

65. Holt, T. N. \& Callan, R. J. Pulmonary arterial pressure testing for high mountain disease in cattle. Vet. Clin. North Am. Food Anim. Pract. 23, 575-596 vii (2007).

66. Duran-Struuck, R. \& Dysko, R. C. Principles of bone marrow transplantation (BMT): providing optimal veterinary and husbandry care to irradiated mice in BMT studies. J. Am. Assoc. Lab. Anim. Sci. JAALAS 48, 11-22 (2009).

67. Graham, B. B. et al. Protective role of IL-6 in vascular remodeling in Schistosoma pulmonary hypertension. Am. J. Respir. Cell Mol. Biol. 49, 951-959 (2013).

68. Tandrup, T., Gundersen, H. J. \& Jensen, E. B. The optical rotator. J. Microsc. 186, 108-120 (1997).

69. Cheever, A. W. Conditions affecting the accuracy of potassium hydroxide digestion techniques for counting Schistosoma mansoni eggs in tissues. Bull. World Health Organ. 39, 328-331 (1968).

70. Howard, C. V. \& Reed, M. G. Unbiased Stereology: Three-Dimensional Measurement in Microscopy (BIOS Scientific Publ, 2005).

\section{Acknowledgements}

Sources of Support: K08HL105536, R03HL133306, R01HL135872, an American Thoracic Society Foundation/Pulmonary Hypertension Association Research Fellowship, Gilead Sciences Research Scholars Program in Pulmonary Arterial Hypertension and the University of Colorado Department of Medicine Early Career Scholars Program (B.B.G.), P01HL014985 (K.R.S., R.M.T. and B.B.G.), and R01HL080396 and R01HL130938 (C.M.E.). PAI-1-luciferase reporter mink lung epithelial cells were kindly provided by Dr Daniel Rifkin (NYU). Schistosome-infected mice were provided by the NIAID Schistosomiasis Resource Center at the Biomedical Research Institute (Rockville, MD) through NIH-NIAID Contract HHSN272201000005I for distribution through BEI Resources.

\section{Author contributions}

R.K., J.P.M., R.M.T. and B.B.G. initiated and designed the study; M.L., B.A.M., A.B. and K.R.S. provided key biological samples; R.K., C.M., B.K., L.G., J.C.R., D.E.K., L.S., L.B., C.M., D.F., M.L., B.A.M., S.R., R.D.B., L.E.M., C.E., D.H.S., J.P.M., W.J.J. and B.B.G. performed the experiments; R.K., T.M.B., W.J.J., R.M.T. and B.B.G. did the statistical and bioinformatics analyses; D.I., T.M.B., W.J.J., K.R.S., R.M.T. and B.B.G. supervised the research; R.K. and B.B.G. wrote the first draft of the manuscript; and all authors contributed to the editing of the revised manuscript, and approved the manuscript.

\section{Additional information}

Supplementary Information accompanies this paper at http://www.nature.com/ naturecommunications 
Competing interests: The authors declare no competing financial interests.

Reprints and permission information is available online at http://npg.nature.com/ reprintsandpermissions/

How to cite this article: Kumar, R. et al. TGF- $\beta$ activation by bone marrow-derived thrombospondin-1 causes Schistosoma- and hypoxia-induced pulmonary hypertension. Nat. Commun. 8, 15494 doi: 10.1038/ncomms15494 (2017).

Publisher's note: Springer Nature remains neutral with regard to jurisdictional claims in published maps and institutional affiliations. (c) (i) This work is licensed under a Creative Commons Attribution 4.0 International License. The images or other third party material in this article are included in the article's Creative Commons license, unless indicated otherwise in the credit line; if the material is not included under the Creative Commons license, users will need to obtain permission from the license holder to reproduce the material. To view a copy of this license, visit http://creativecommons.org/licenses/by/4.0/

(C) The Author(s) 2017 